\title{
Gene variants associated with acne vulgaris presentation and severity: a systematic review and meta-analysis
}

\author{
Anna Hwee Sing Heng, Yee-How Say, Yang Yie Sio, Yu Ting Ng and Fook Tim Chew ${ }^{*}$
}

\begin{abstract}
Background: Multiple factors have been attributed to acne vulgaris predisposition and individual variations in the severity of skin symptoms, and genetics stood out as one of the major factors.

Methods: We performed a systematic review on the genes and their variants that have been investigated for association with acne presentation and severity. A random-effect meta-analysis using the allele model (minor allele vs. major allele) was also conducted to provide an overall estimation of risk effects of frequently reported gene variants. This included a subset data of 982 acne cases and 846 controls extracted from our existing GWAS database on various allergic and skin diseases among Singapore Chinese.

Results: Systematic review of 51 articles covering Asians and Caucasians found 60 genes/loci and their 100 variants implicated in acne; majority of them were in the intron, coding region/missense, and promoter regions. The commonly studied candidate genes/gene families include tumor necrosis factor (TNF), and the interleukin (IL) and cytochrome P450 (CYP) gene families. Our meta-analysis showed that most of the analyzed gene variants exhibited insignificant pooled odds ratio (POR) and significant heterogeneity between studies. Nevertheless, we found that TNF rs1800629 A allele carriers and CYP17A1 rs743572T allele carriers had significantly reduced mild acne risk [pOR: 0.60; 95\% Confidence Interval (Cl): 0.33-0.86] and severe acne risk (pOR: 0.59; 95\% Cl: 0.40-0.79), respectively, across populations. Overall, FST (follistatin) rs629725 A allele poses a significantly modest increased risk for acne presentation (pOR: 1.19, 95\% Cl: 1.14, 1.23), but neither TIMP2 (TIMP metallopeptidase inhibitor 2) rs 8179090 nor CYP1A1 rs4646903 (pOR: 0.96, 95\% Cl: $0.80-1.12$; pOR: $0.95,95 \%$ Cl: $0.83,1.08$ ), respectively. We discovered 15 novel SNPs in the $3^{\prime}$ UTR region of the Toll-like Receptor 4 gene (TLR4) associated with acne presentation.
\end{abstract}

Conclusions: This systematic review and meta-analysis suggest that genes influencing inflammatory responses, specifically TNF, and genes influencing the function and activity of sebaceous glands, specifically CYP17A1 and FST, have potential risk variants for acne presentation and severity across populations. Understanding the genetic susceptibility factors and biological pathways involved in the pathogenesis of acne will help us to gain insights into developing effective acne treatments.

Keywords: Acne vulgaris, Gene, Genome-wide association study, Single nucleotide polymorphism, Risk factors

*Correspondence: dbscft@nus.edu.sg

Allergy and Molecular Immunology Laboratory, Lee Hiok Kwee Functional Genomics Laboratories, Department of Biological Sciences, Faculty of Science, National University of Singapore, Block S2, Level 5, 14 Science Drive 4, Lower Kent Ridge Road, Singapore 117543, Singapore

\section{Background}

Acne vulgaris (acne) is a highly prevalent, chronic inflammatory skin disease affecting the pilosebaceous unit, mainly at the face, neck, upper trunk and back [1]. The severity of acne is characterized by the number 
of non-inflammatory closed and open comedones, inflammatory pustules and papules, as well as residual pathology like nodules and cysts [1,2]. Chronic acne inflammatory symptoms like scars, erythema and hyperpigmentation, lead to psycho-social consequences such as depression, anxiety [3] and unemployment [4].

The etiology of acne is a complex interplay between androgen-induced sebum production, follicular keratinization, inflammation, and colonization of pilosebaceous follicles by Cutibacterium acnes (formerly Propionibacterium acnes) [1]. Acne is a multifactorial disease, and we have recently reviewed that the epidemiological risk factors for acne and acne severity include demographics, genetics/hormonal, dietary habits and lifestyle factors [5]. Of note, earlier twin [6] and family studies [7, 8] have established that acne susceptibility has a strong genetic component. Multiple case-control familial studies and twin studies involving numerous ethnicities showed strong heritability with estimates upwards of 78\% [6-8], while concordance between monozygotic twins compared with dizygotic twins was higher for both acne presentation and severity [8]. Recent candidate gene studies and genome-wide association studies (GWAS) further revealed that the genes and loci associated with acne presentation and severity influence the function and activity of sebaceous glands or immune and inflammatory responses (reviewed in 9,10). Two such gene susceptibility loci were found in Han Chinese [9], while up to 15 were found in Caucasians [10-12].

Reviews on the genes and gene variants associated with acne presentation and severity are scarce [13-15]. Therefore, we hereby performed a systematic review on that, and also performed a random-effect meta-analysis on selected risk gene variants, which included a subset data of 982 acne cases and 846 controls extracted from our existing GWAS database on various allergic and skin diseases among Singapore Chinese. Lastly, we discussed the biological pathways implicated by these genes in the pathogenesis of acne.

\section{Methods}

\section{Literature search}

The articles reviewed were retrieved from searches conducted on the Web of Science database on 19 October 2020. In the first search, the search criteria used were: document type 'article', search terms 'acne' in the topic and 'polymorphism' in the title. Additional searches using the following criteria-document type 'article' and either the search terms 'acne' and 'predisposition' in the topic or search terms 'acne risk' and 'gene' in the topic-were also conducted. The searches aimed to garner articles about polymorphisms associated with acne presentation (presence/absence of acne vulgaris, severe acne, or teenage acne) and acne severity (mild, moderate, severe grades), thus more general search terms were chosen. Monogenic disorders and syndromes associated with (severe) acne (such as Apert syndrome, Frank-ter Haar syndrome and Winchester syndrome), and genes and gene variants associated with co-morbidities of acne such as endocrine system syndromes were not included in the systematic review as they have been reviewed recently [15]. Quality of included studies was evaluated using the JBI Critical Appraisal Tool Checklist [16] containing eight criteria. All papers selected for inclusion in the systematic review (that is-those that meet the inclusion criteria described above) were subjected to rigorous appraisal by two critical appraisers.

\section{Criteria for meta-analysis}

Studies were included in the meta-analysis if they satisfied the following inclusion criteria: 1. Gene variants that were involved in at least two case-control studies that evaluated acne presentation and/or acne severity; 2 . Genotype/allele frequencies were available for cases and controls; 3 . The distribution of genotypes in the control group fulfils the Hardy-Weinberg equilibrium (HWE); 4. Studies that have provided an estimation of effect size, such as the odds ratio (OR) with corresponding $95 \%$ confidence intervals (CI); or if not reported in article, derived from statistical analysis using genotype/allele frequencies or from communication with corresponding authors; 5 . When publications involved the overlapping data sets, only the study with the largest number of participants was included. The supporting PRISMA checklist is available as Additional file 1: Table S1.

\section{Data extraction and retrieval}

The following data were extracted: the name of the first author, year of publication, country of origin, ethnicity, genotype frequencies in acne cases and controls or acne severity grades, presence/absence of association, $\mathrm{OR}, \mathrm{CI}$ and $p$ values for genotypes and alleles. Additional information about the gene variants were retrieved from National Centre for Biotechnology Information (NCBI) dbSNP or European Bioinformatics Institute (EBI) Ensembl databases: chromosomal location, common name of variant, rs number (if available), most severe consequence. Availability of expression quantitative trait loci (eQTL) data for the SNPs and the tissue types was sourced from the GTex Portal (available at https:// gtexportal.org/home/). Gene ontology analysis/network analysis was performed for the list of genes using the online Database for Annotation, Visualization and Integrated Discovery (DAVID) v6.8 software (available at https://david.ncifcrf.gov/), with the highest classification 
stringency and other default settings for functional annotation clustering.

A subset of genotyping data from our existing GWAS database on various allergic and skin diseases among Singapore Chinese were extracted for 982 acne cases and 846 controls (full details in Additional file 2). After exclusion, a total of 4517 SNPs were analyzed and logistic regression analysis was conducted using the plink software to investigate the association between the minor allele counts and acne presentation.

\section{Statistical analysis for meta-analysis}

To perform the random-effect meta-analysis, we extracted the OR and $95 \%$ CI reported from each study of interest. Where not reported, OR and CI were calculated with binary logistic regression test using $\operatorname{IBM}^{\circledR}$ SPSS $^{\circledR}$ Statistics software (IBM Inc., NY). For consistency, we estimated the association based on the allele model (minor allele $v s$. major allele). These study findings were combined using the random effect model and the pooled OR and $95 \%$ CI were computed using the Stata/MP ${ }^{\circledR}$ version 16.0 statistical software (StataCorp LLC, TX). We used a chi-square-based test to examine any heterogeneity presented in the pooled risk estimate, with the inconsistency index $\left(\mathrm{I}^{2}\right)$ also computed; $\mathrm{I}^{2} \geq 50 \%, p<0.05$ was considered statistically significant. To evaluate whether the association showed any ethnicity-specific or severity-specific effects, we analyzed the data for separate subgroups defined by ethnicity or acne severity grade. Sensitivity analysis was performed by excluding individual studies and recalculating the results in order to assess the stability of the results. It was performed only for SNPs with $\geq 4$ studies as we have set the criteria that the meta-analysis should only be performed for $\geq 3$ studies. Publication bias was assessed using Begg's funnel plots and Egger's test.

\section{Results}

\section{Overview of systematic review and meta-analysis of included studies}

The flow chart that displays the study selection process is shown in Fig. 1. The three searches identified 64, 45 and 115 results respectively; however, there were overlaps in the results obtained from the three searches. After excluding articles describing other diseases, types of acne and acne treatments; articles with poorly specified study design and methods; repeated articles and other irrelevant articles, 46 unique articles remained. Five crossreferencing articles were also included, thus a total of 51 articles were included in the systematic review. Excluding 26 articles that had gene variants that were involved in less than two case-control studies (excluding ours) or had OR and CI values that could not be derived or not reported by authors, 25 articles were included in the meta-analysis.

Sixty genes and their 100 variants investigated in the reviewed articles and their associations with acne presentation and acne severity are summarized in Table 1 . The most common region where the variants are located is the intron, followed by the coding region-missense, promoter, intergene, coding region-synonymous, $3^{\prime}$ UTR and non-coding exon region. Populations covered in the studies included Asians, Europeans and North Americans, but not Africans, South Americans and Oceanians. DAVID gene ontology analysis revealed 15 functional annotation clusters (Additional file 3: Figure S2). Most of the genes identified in the reviewed studies and from DAVID analysis can be categorized into two major biological function groups, namely 'immune and inflammatory responses' and 'sebaceous gland function and activity' (Table 1). Genes and gene variants from different populations studies and their differing association findings will be first described, with meta-analysis results and in vitro findings investigating the biological functional consequences of these SNPs included as well, where available.

Sensitivity analysis showed that the corresponding pooled ORs were not significantly altered by sequential omission of individual studies (data not shown). They remained significant or insignificant even after sequential omission of individual studies. The results of sensitivity analysis indicated the stability of our results. Begg's funnel plot and Egger's test showed that there was statistically significant publication bias for the meta-analysis of TNF rs1800629 acne presentation, mild acne and severe acne; SELL rs7531806; PPARG rs1801282; and CYP17A1 rs743572 acne presentation, moderate acne and severe acne. However, the shape of the funnel plots for the rest of the SNPs analyzed seemed symmetrical and Egger's test $p$ value $>0.05$, indicating that there were no evidences for obvious publication bias (Additional file 3: Figure S3).

\section{Genes and gene variants involved in immune and inflammatory responses Tumor necrosis factor (TNF)}

Some of the genes implicated in acne presentation and acne severity are involved in immune and inflammatory responses. The pro-inflammatory factor, tumor necrosis factor $(T N F)$ is the most frequently studied gene in the reviewed articles. In particular, the studies investigated variations at positions $-238,-308,-857,-863$ and -1031 localized in the promoter region of TNF, meaning that they may affect the gene expression positively or negatively, conferring a protective or detrimental effect on acne. 


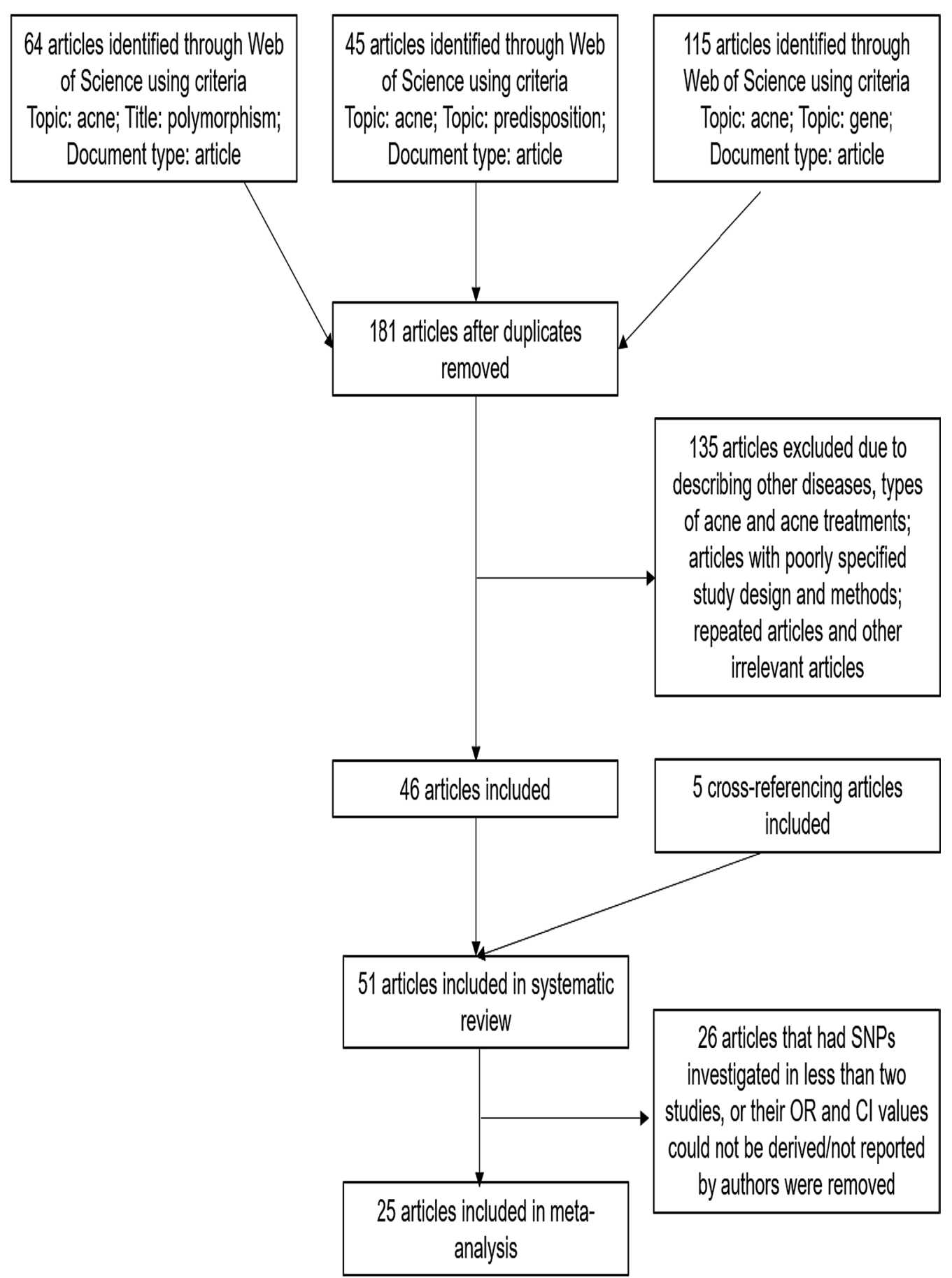

Fig. 1 Flow chart of literature search and study selection

The -308 SNP (rs1800629) is the most common among all and is a potential risk factor among Caucasians, as shown by two meta-analyses [37, 62], but the conclusions are different in other populations. Several studies found a significant association with acne alone [24, 36, 37] or both acne and acne severity [33], but other studies found insignificant associations with acne severity alone $[24,35,36]$, acne alone [34] or both acne and acne severity [22]. Furthermore, the results of one study suggested the possibility of gender differences in the association of -308 SNP with acne as a significant association was observed for females, but not for males or the combined 


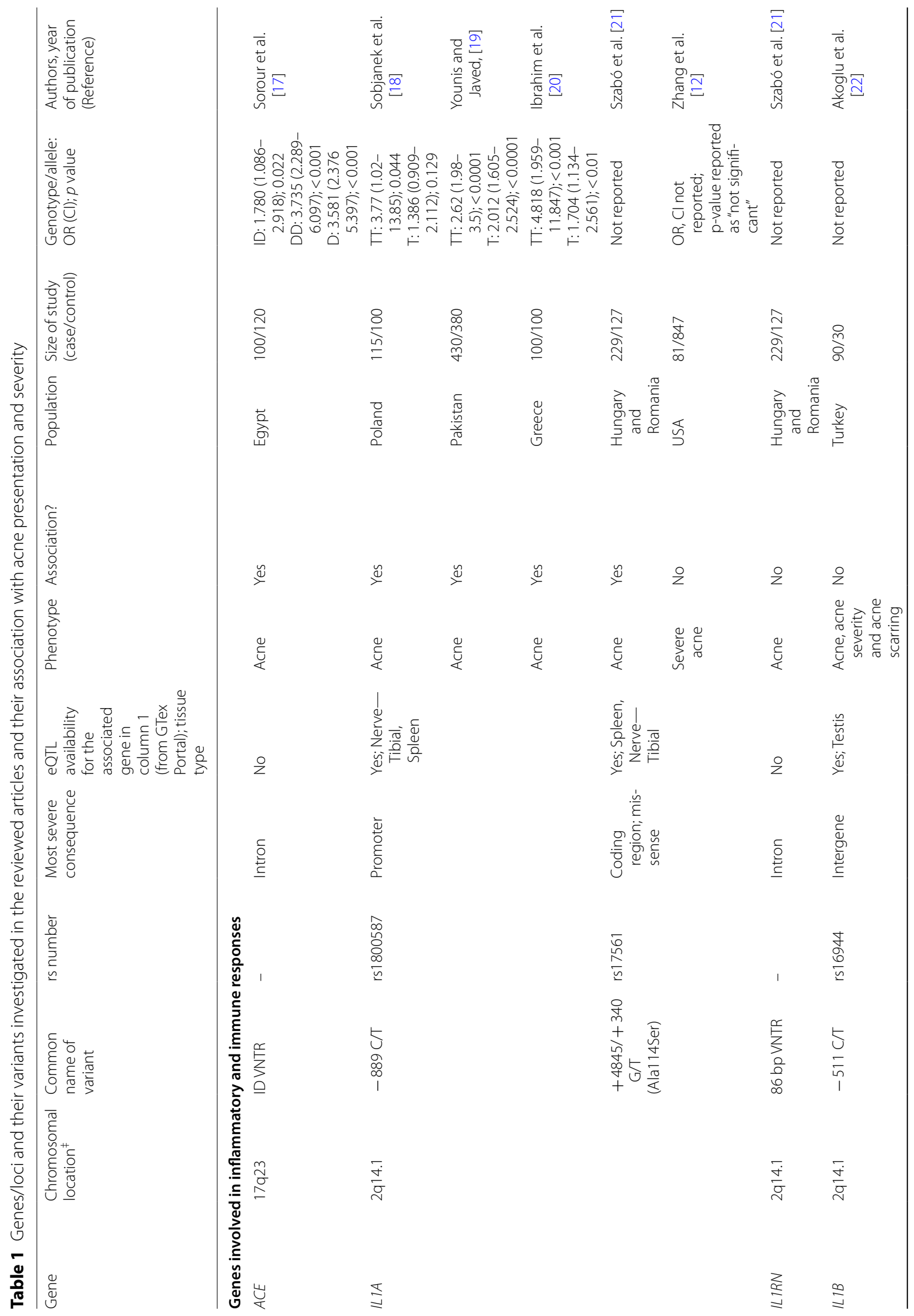




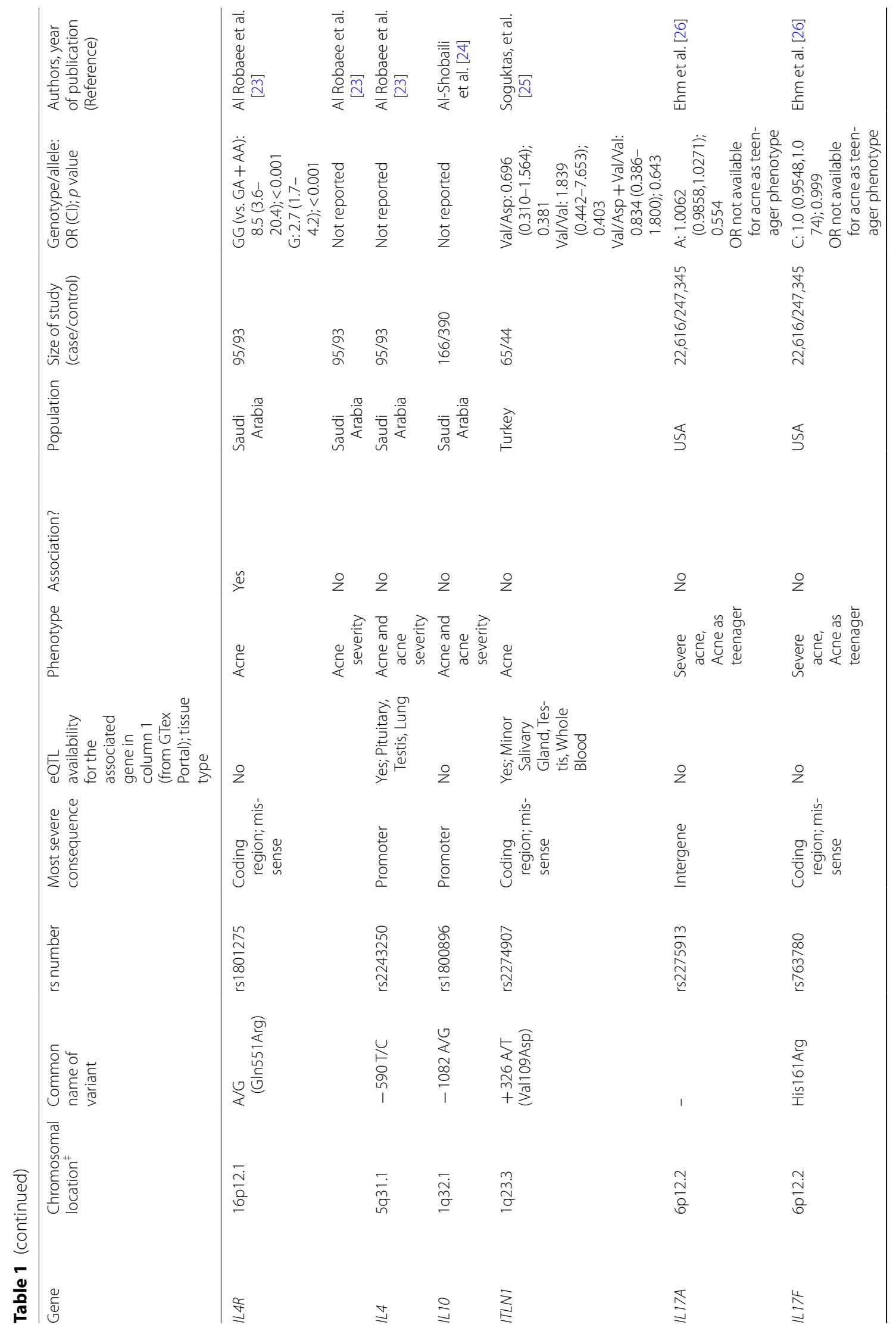




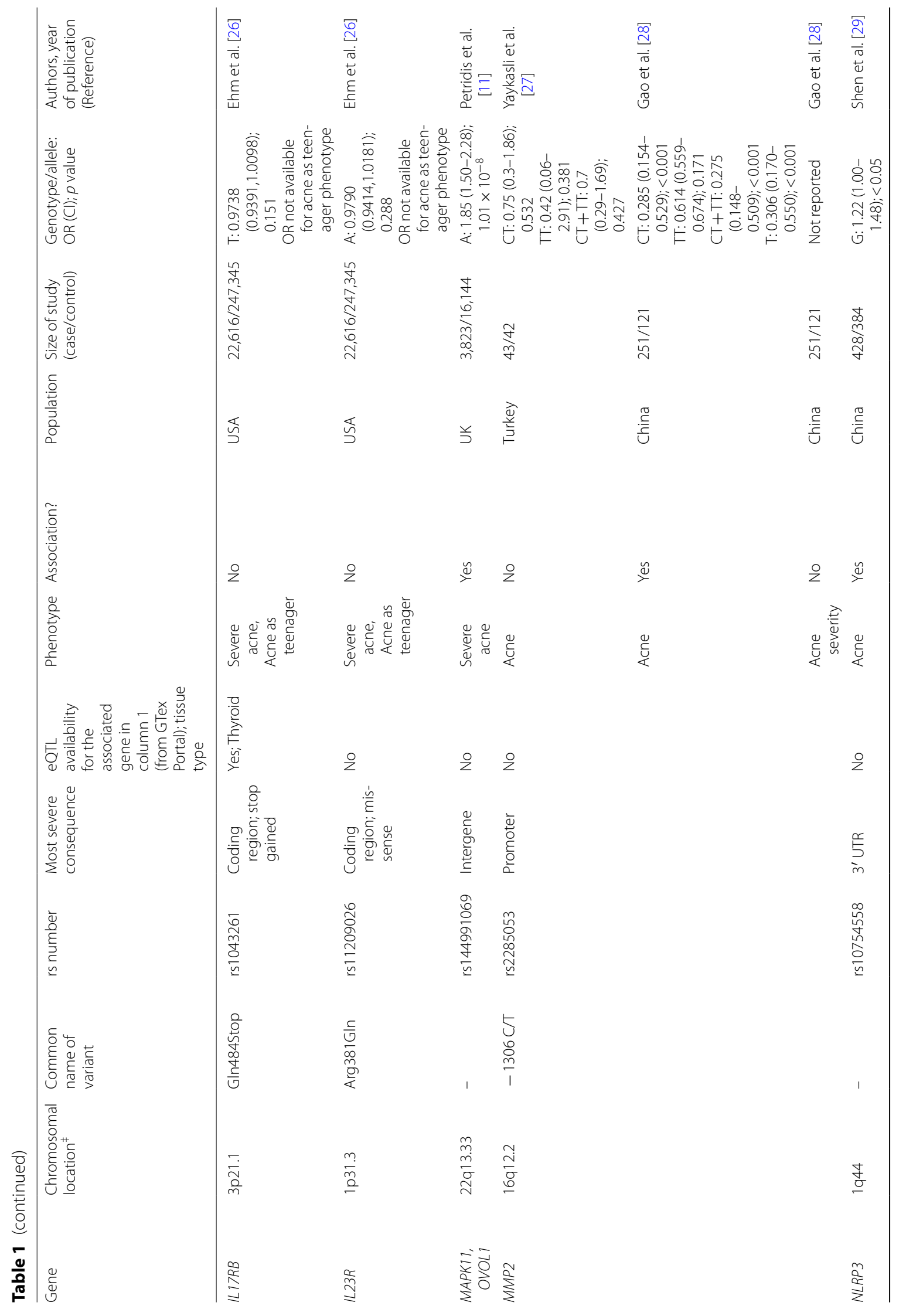




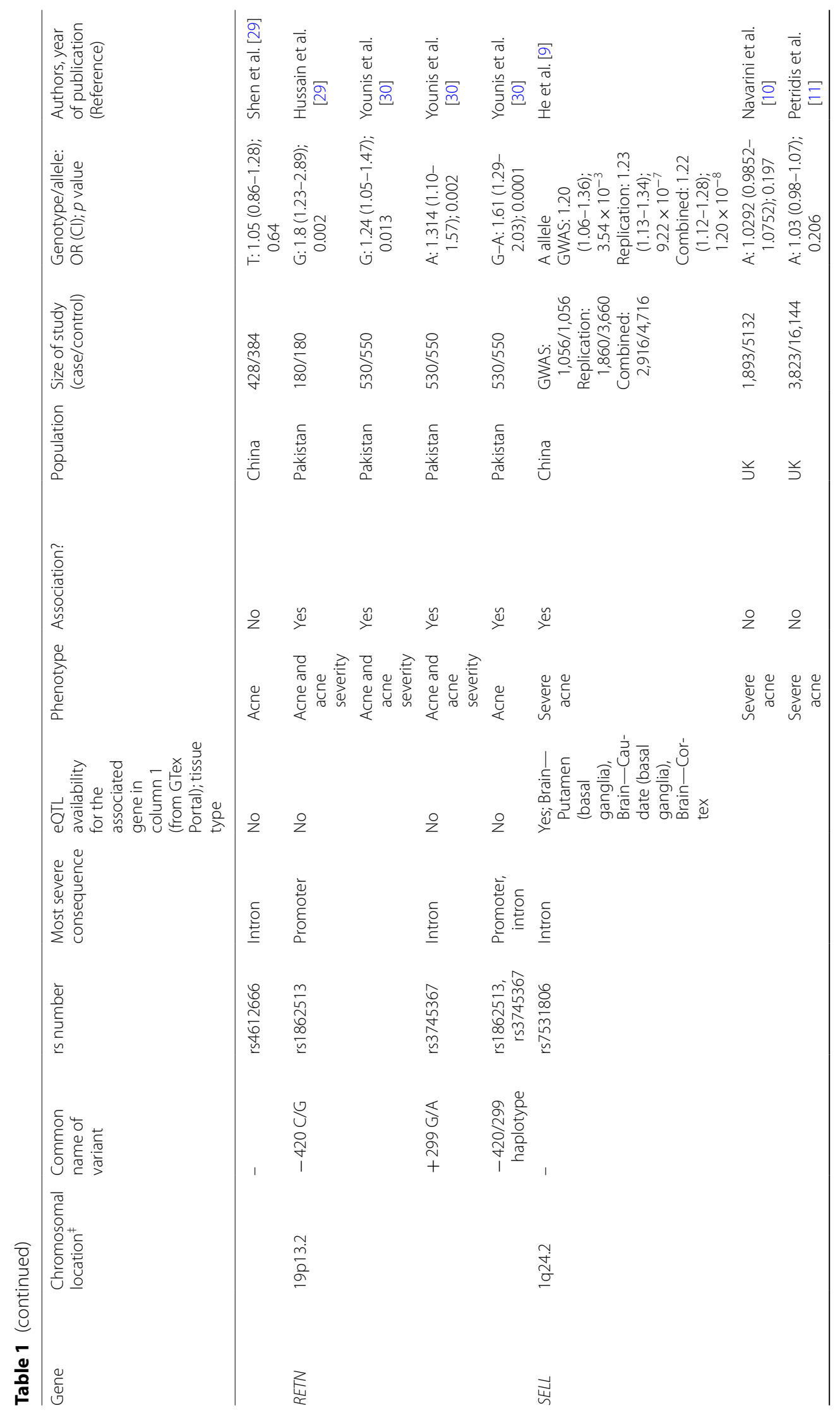




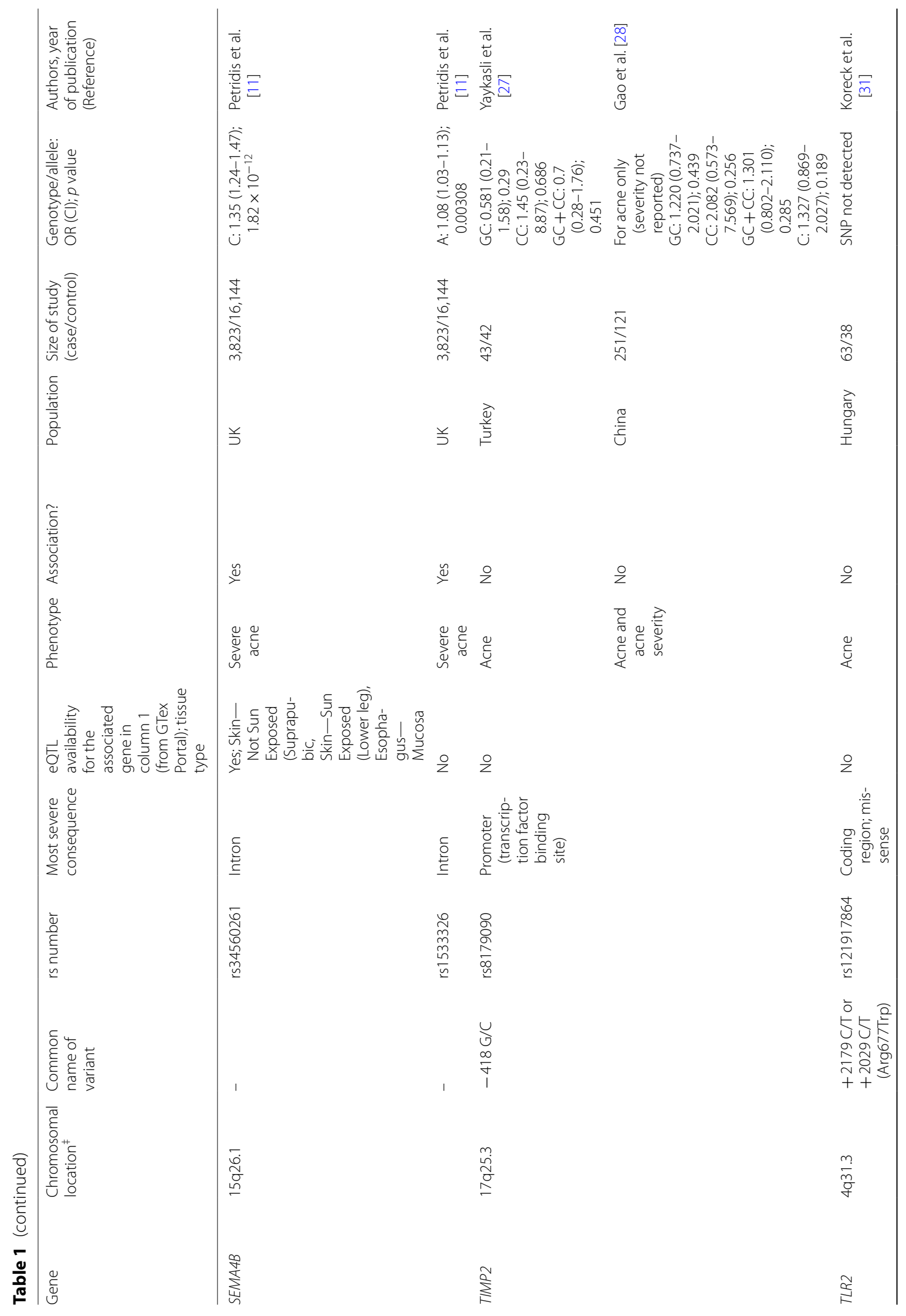




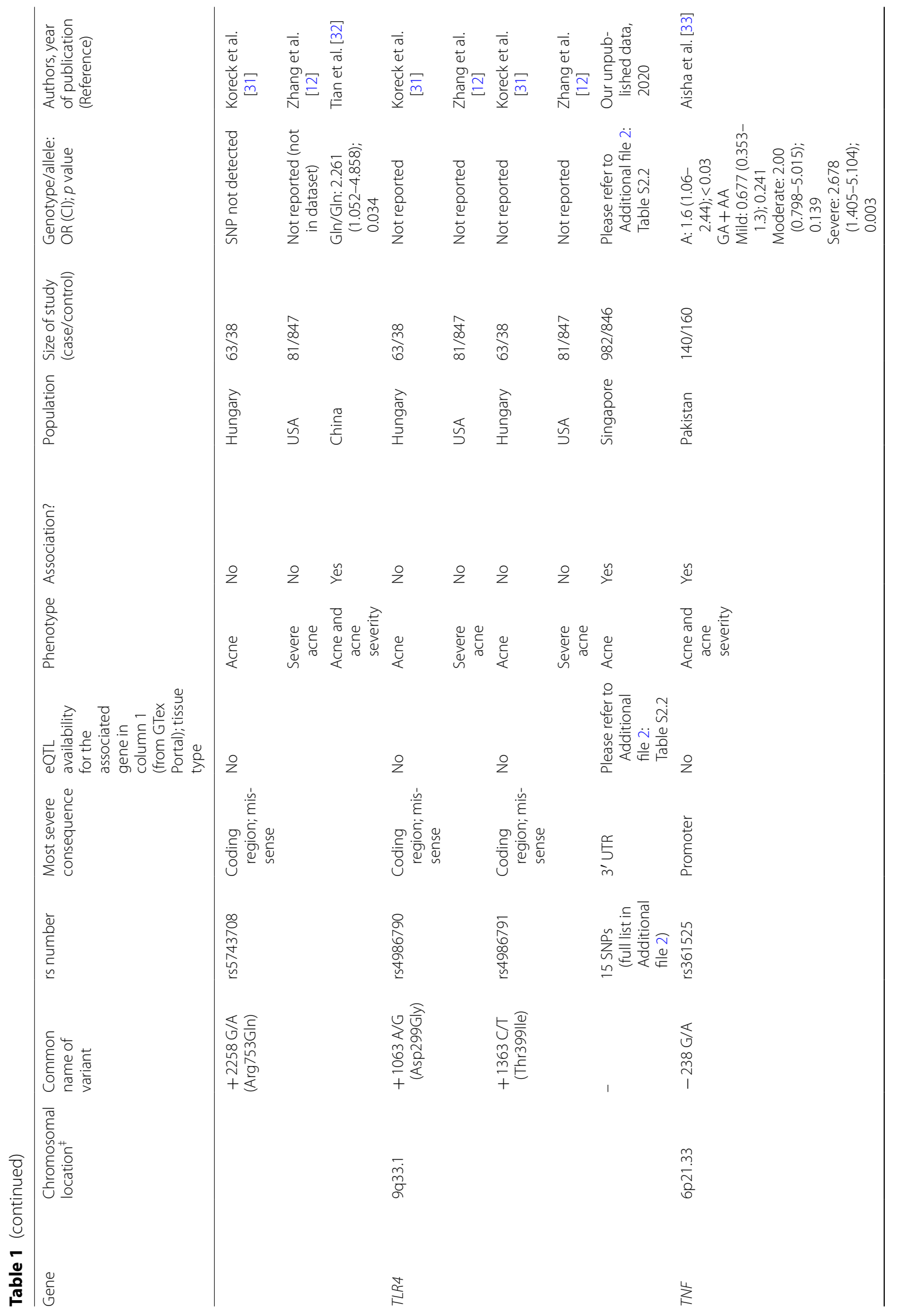




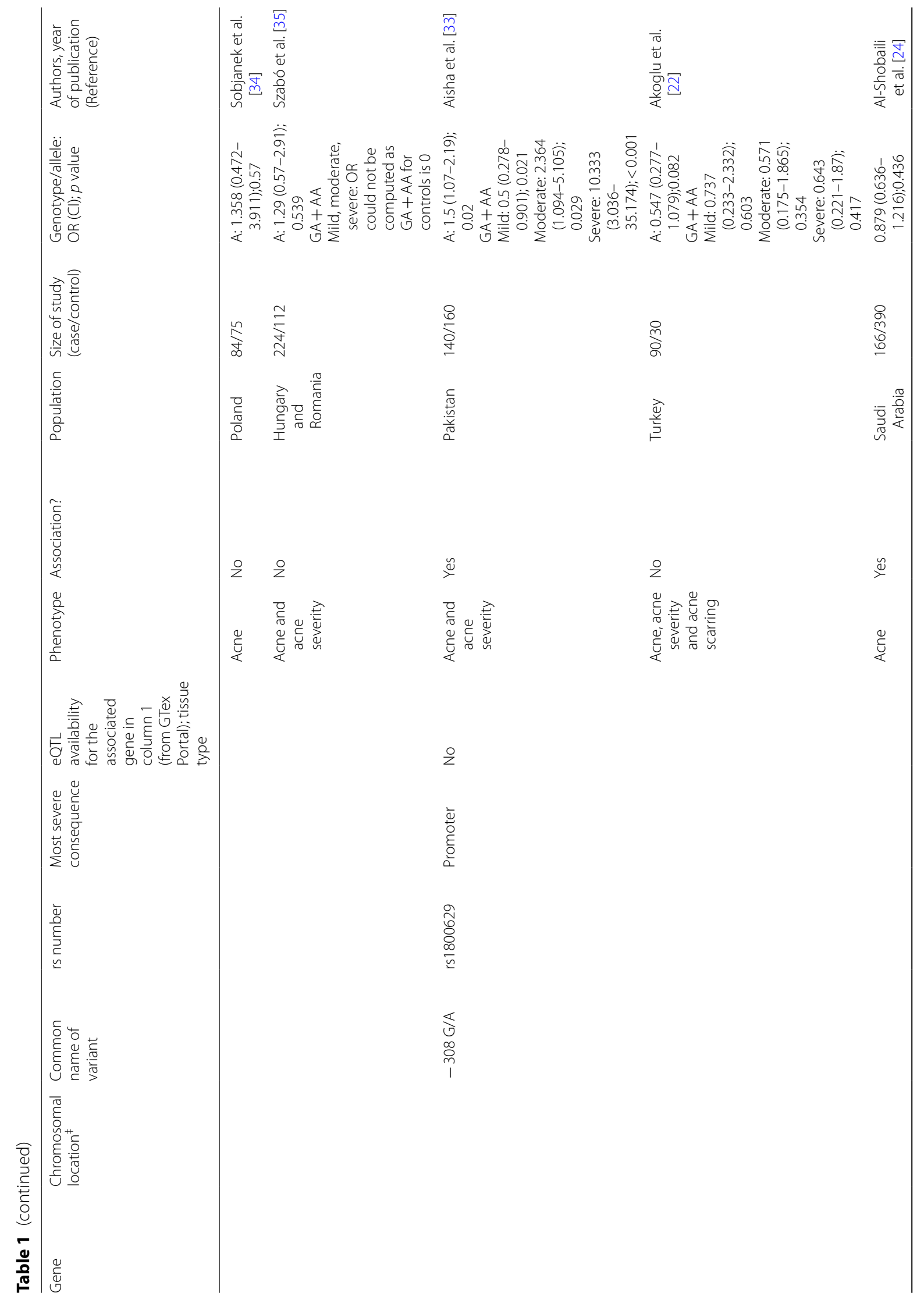




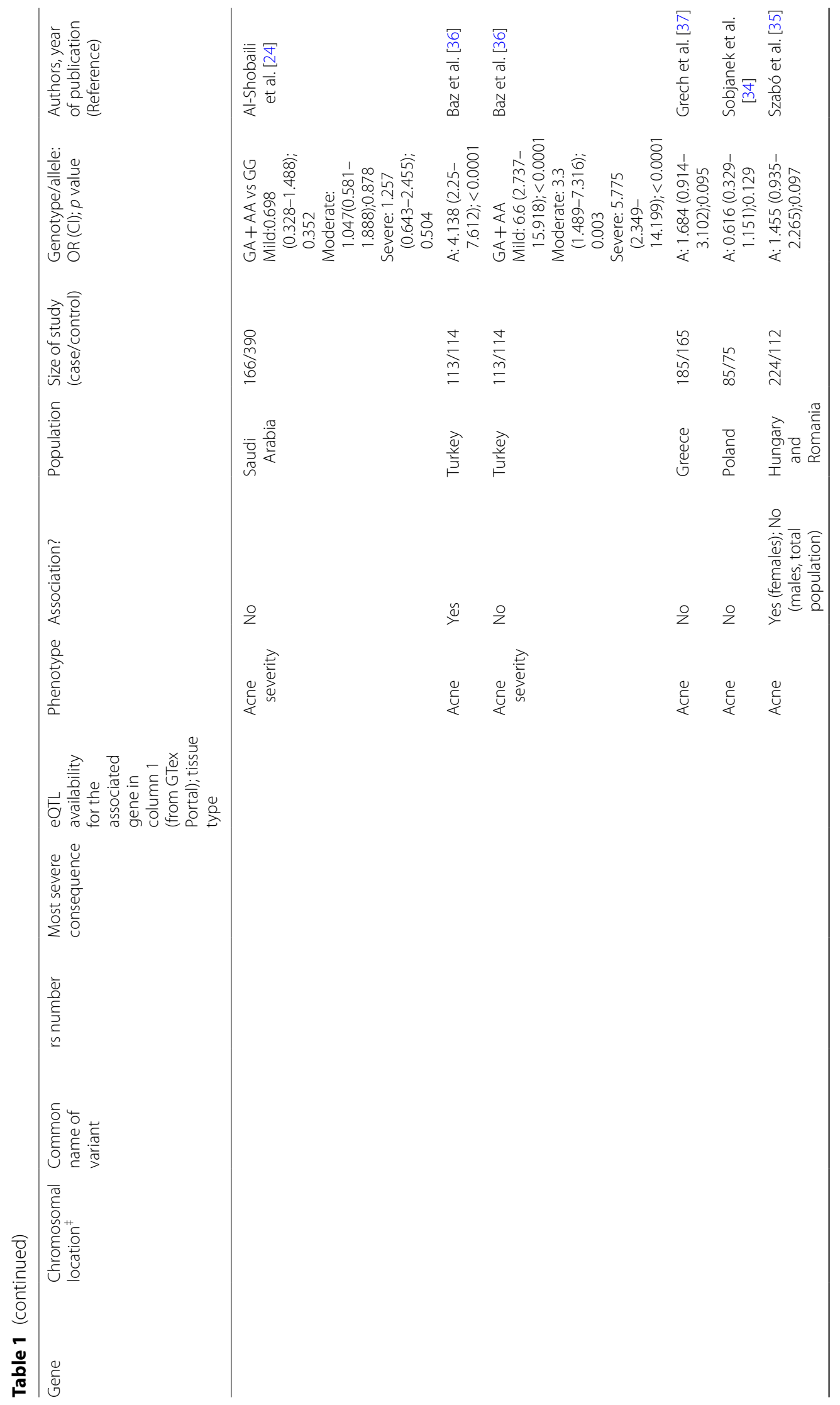




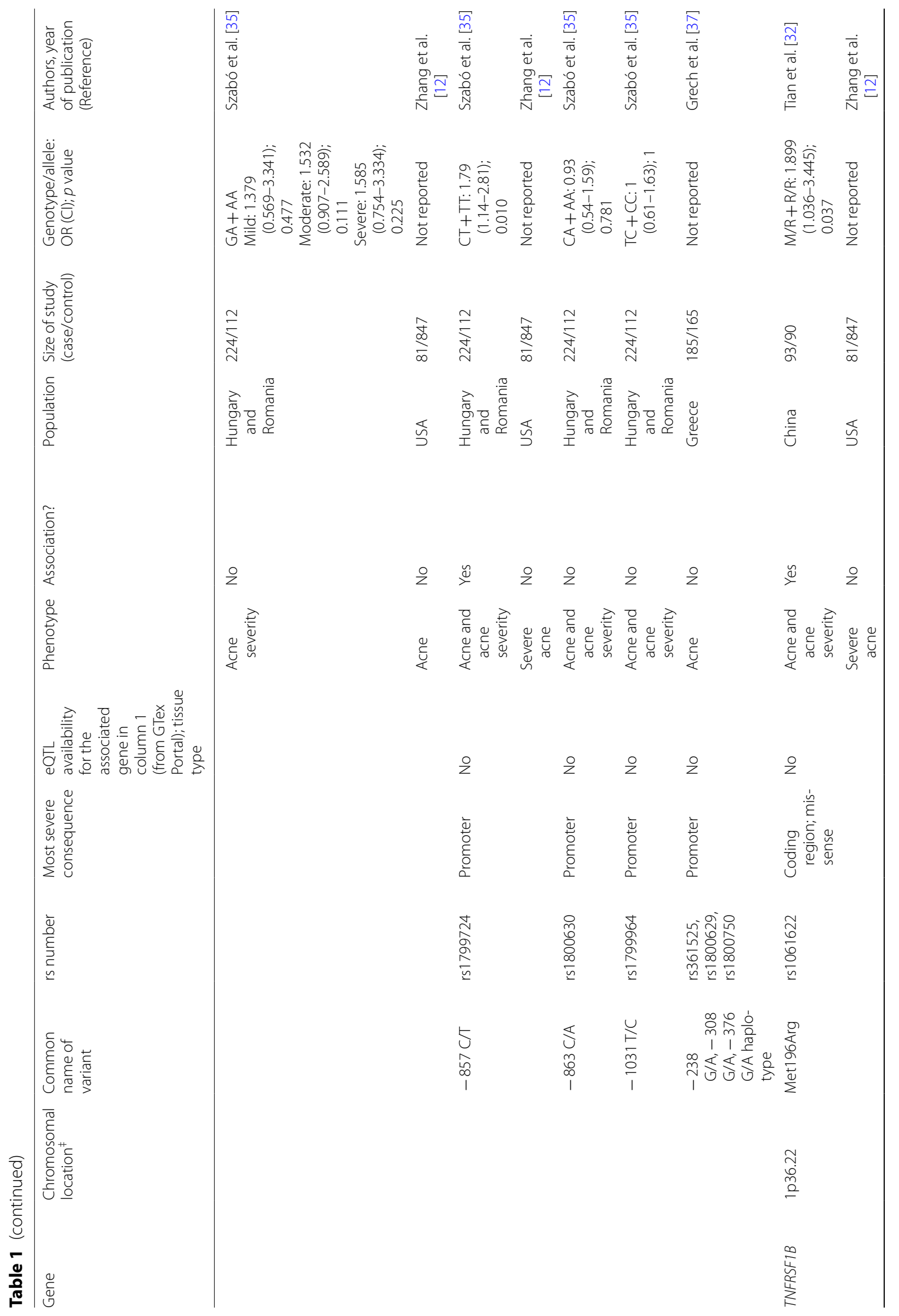




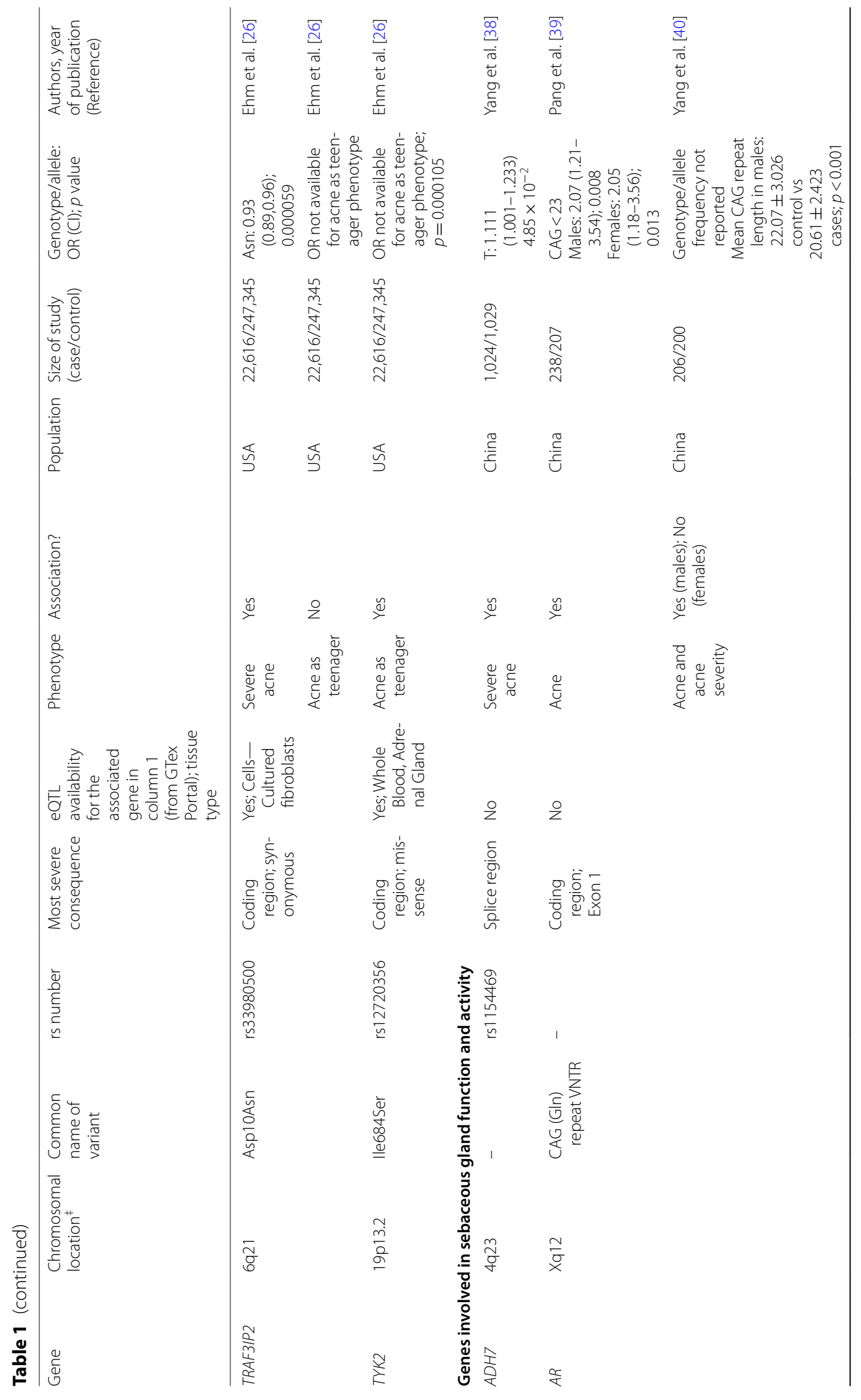




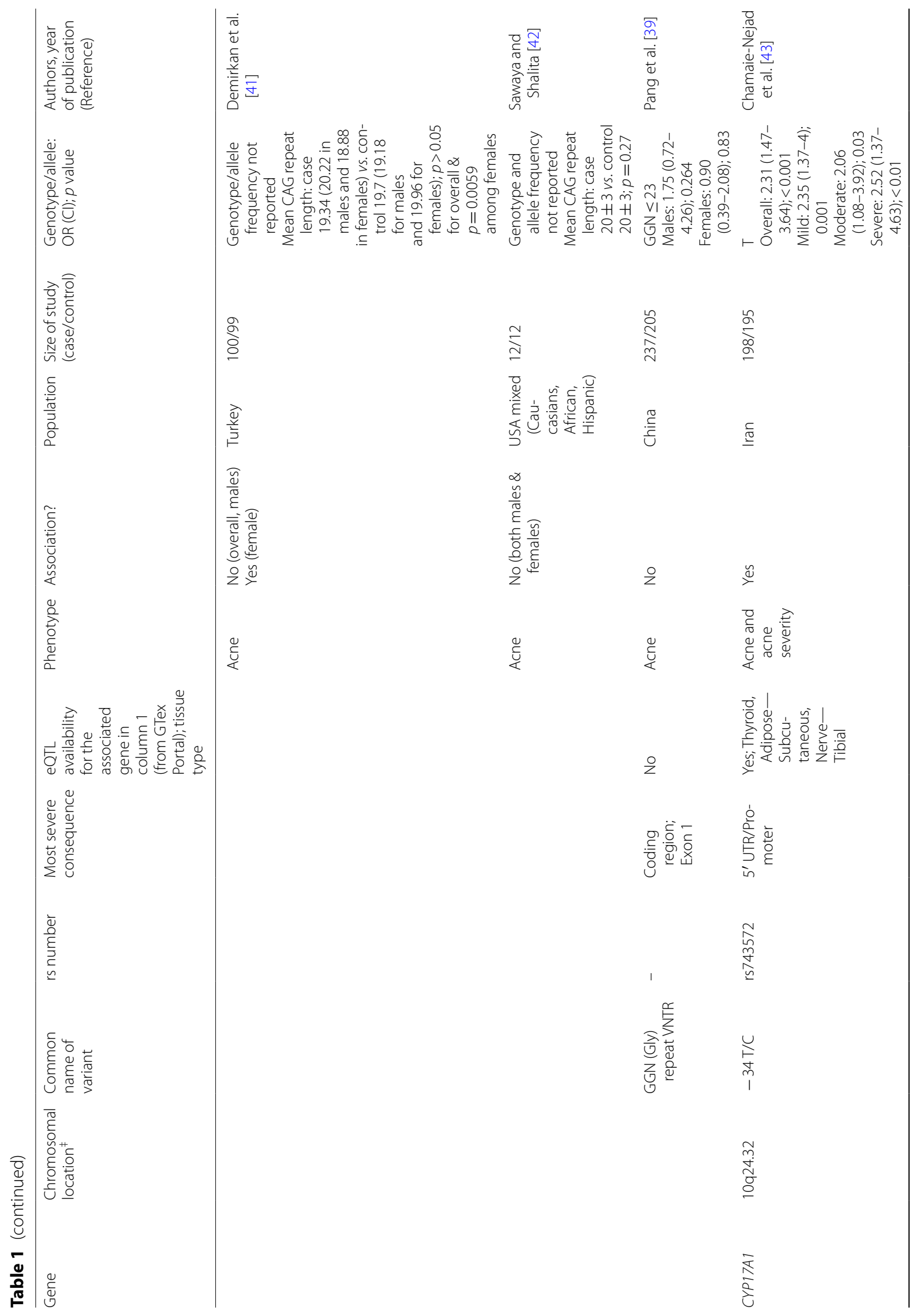




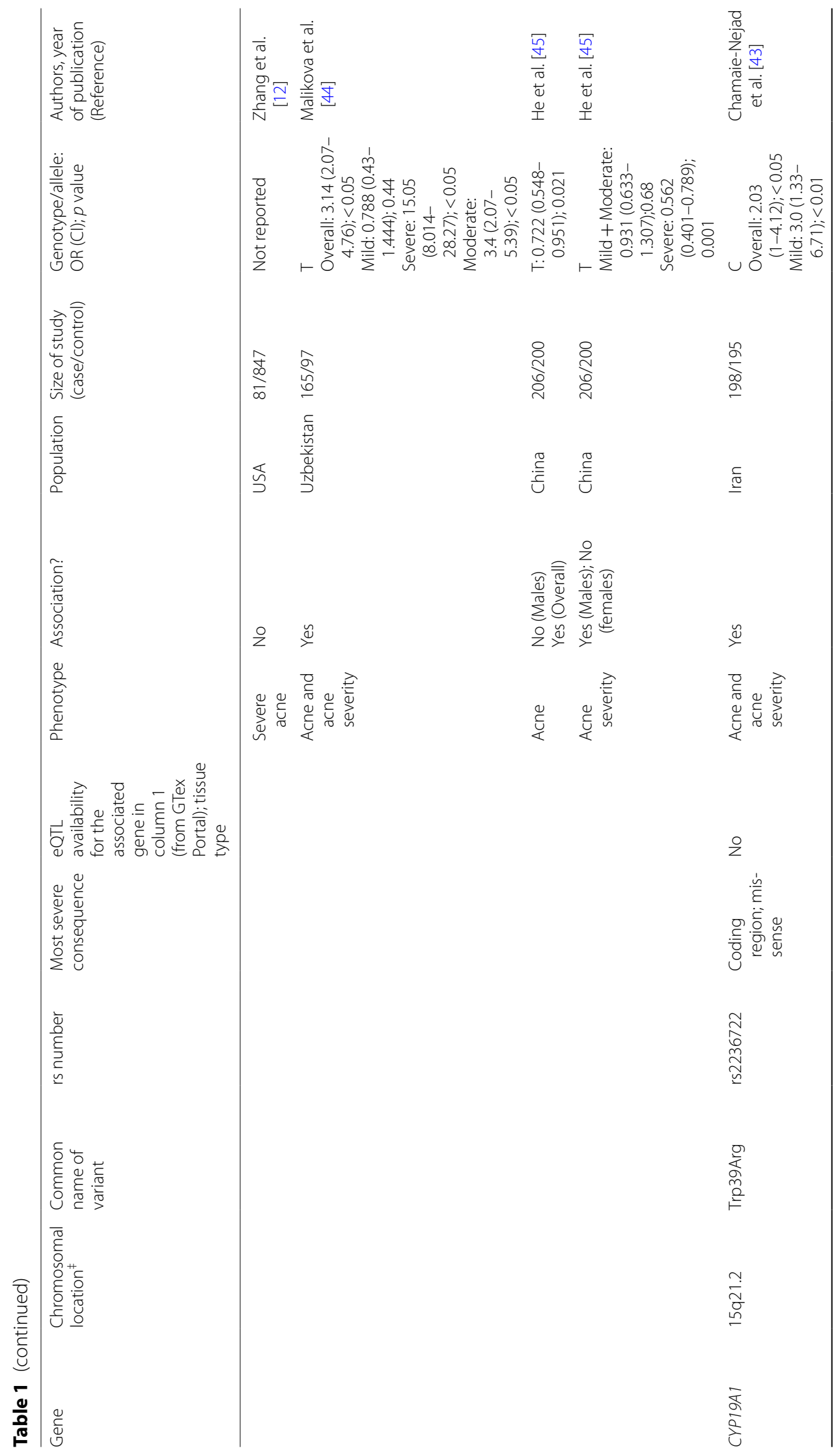




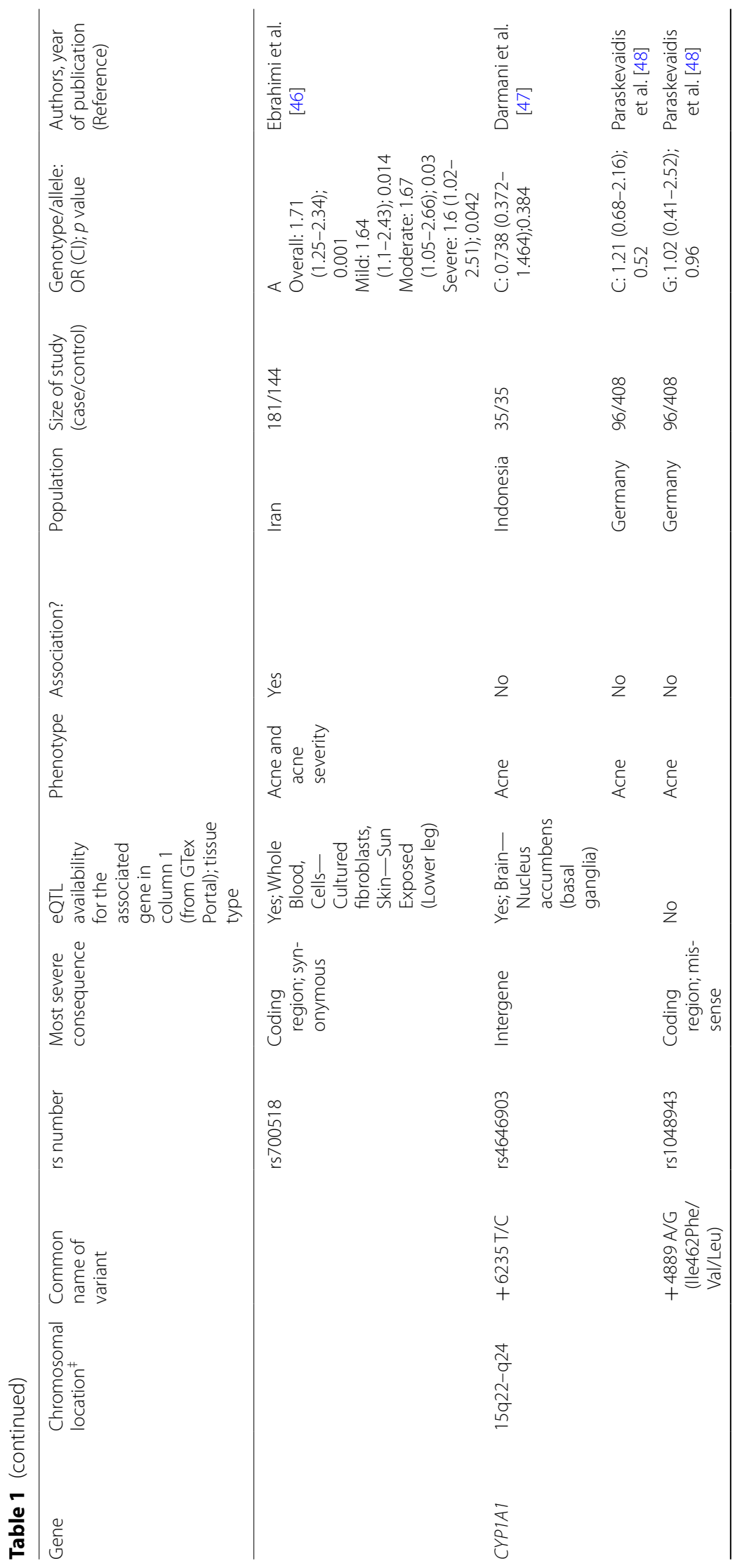




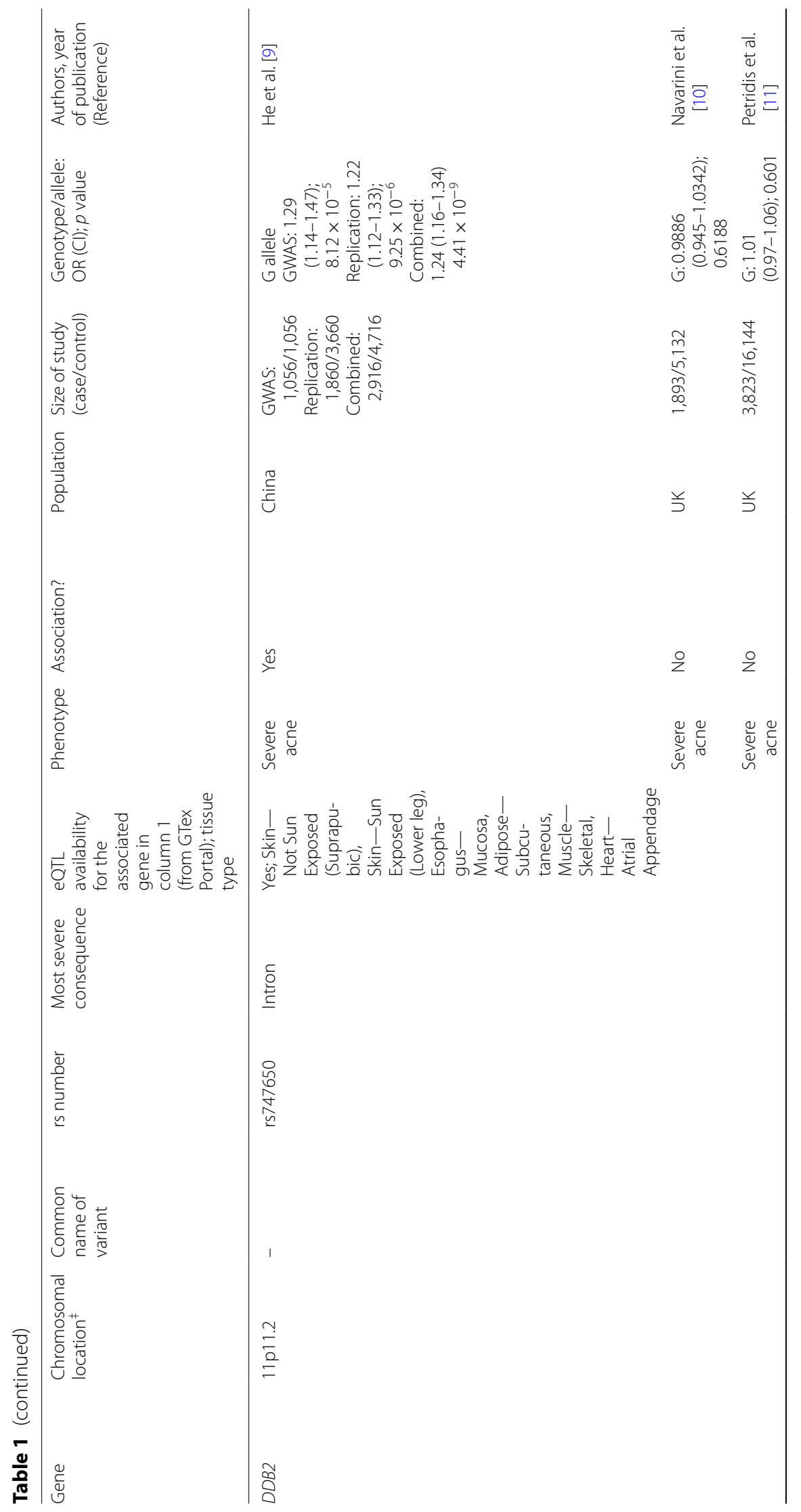




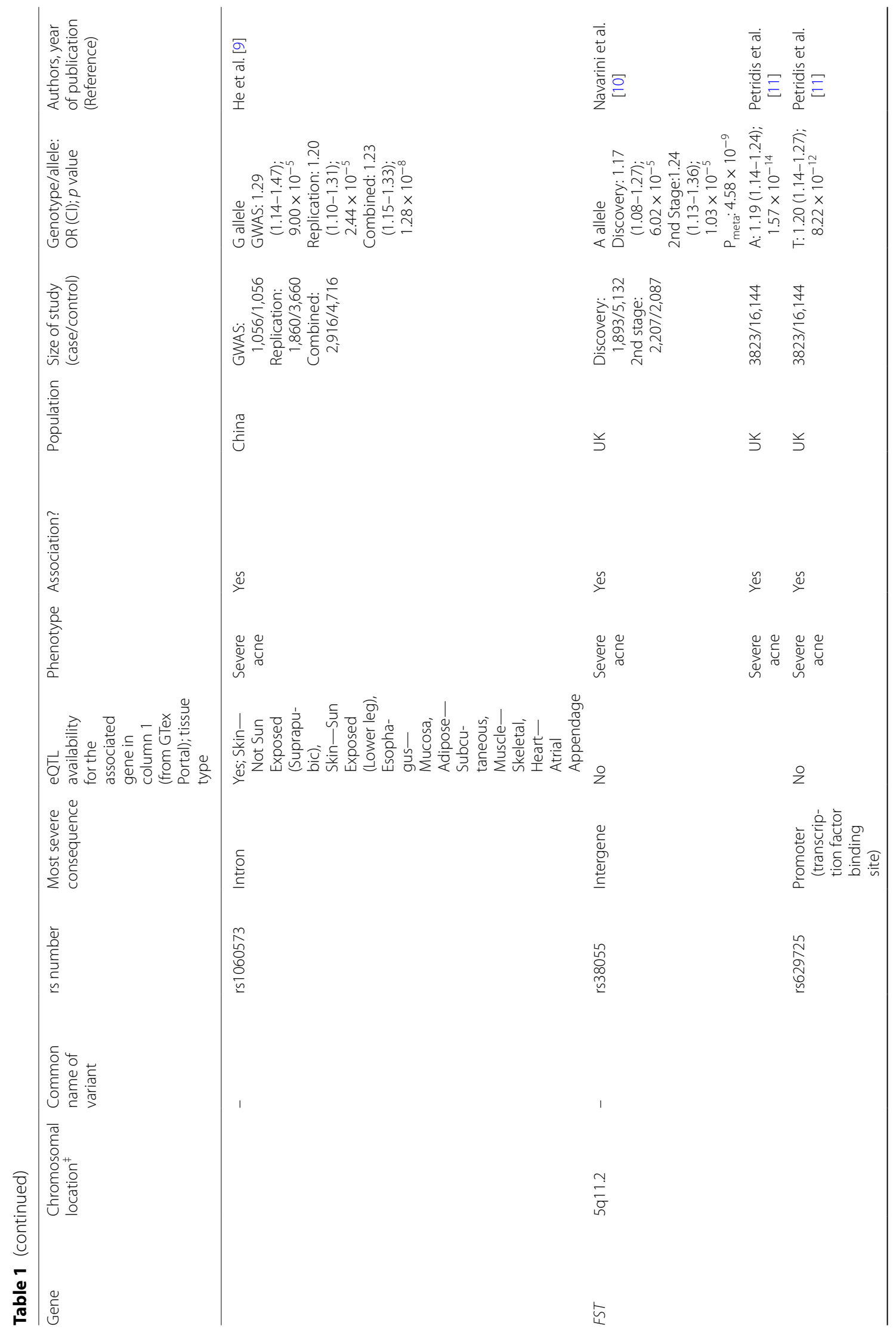




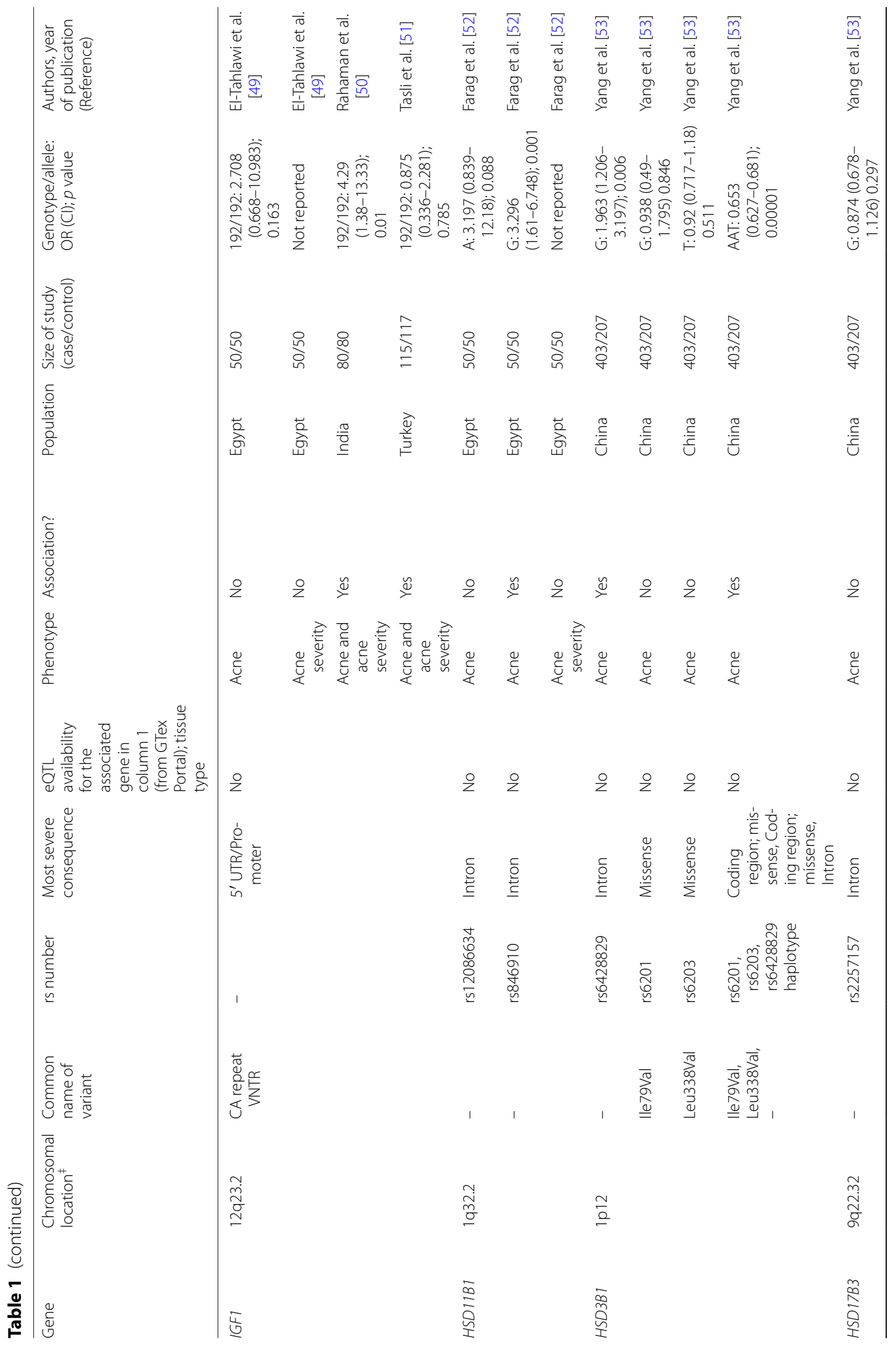




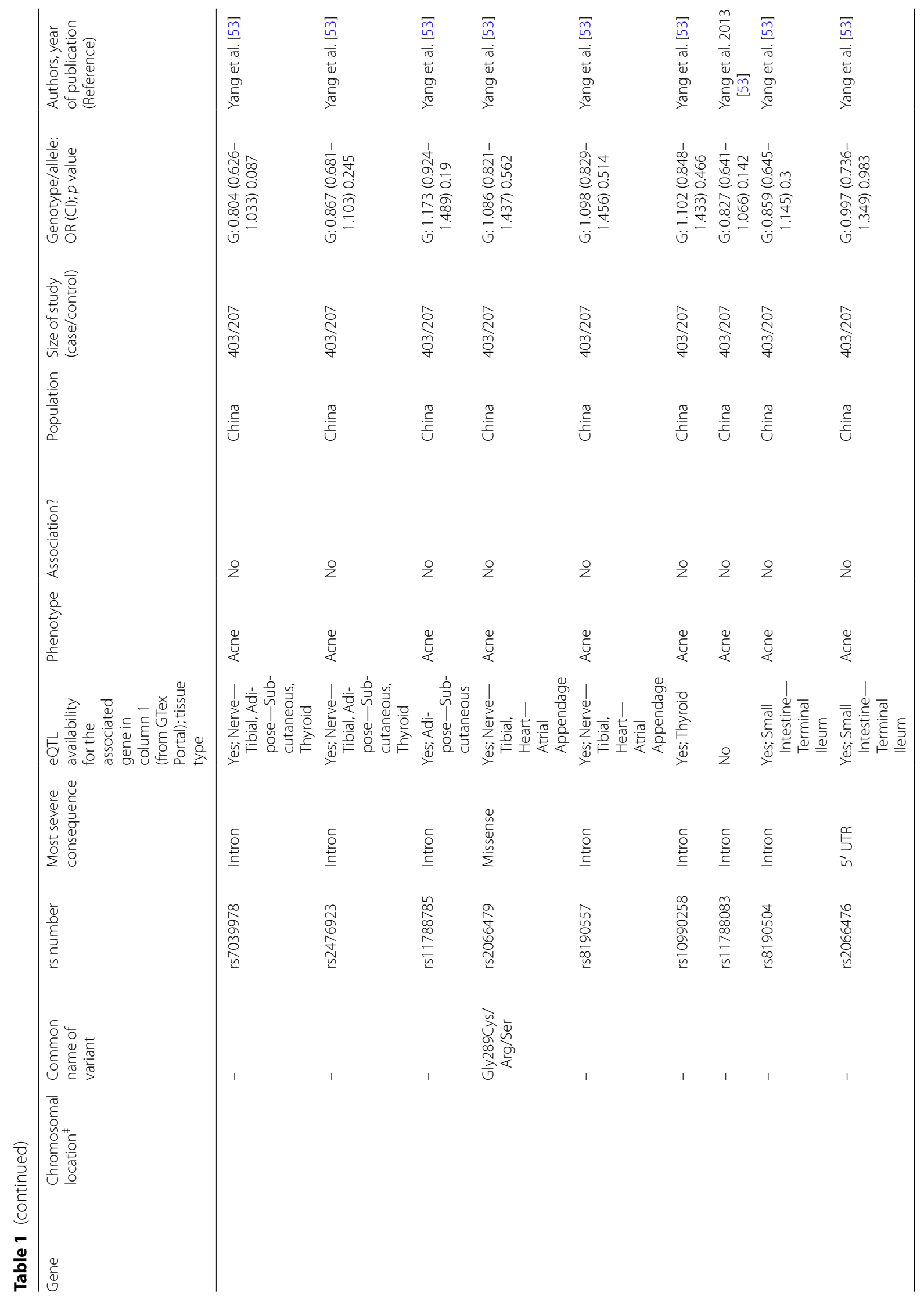




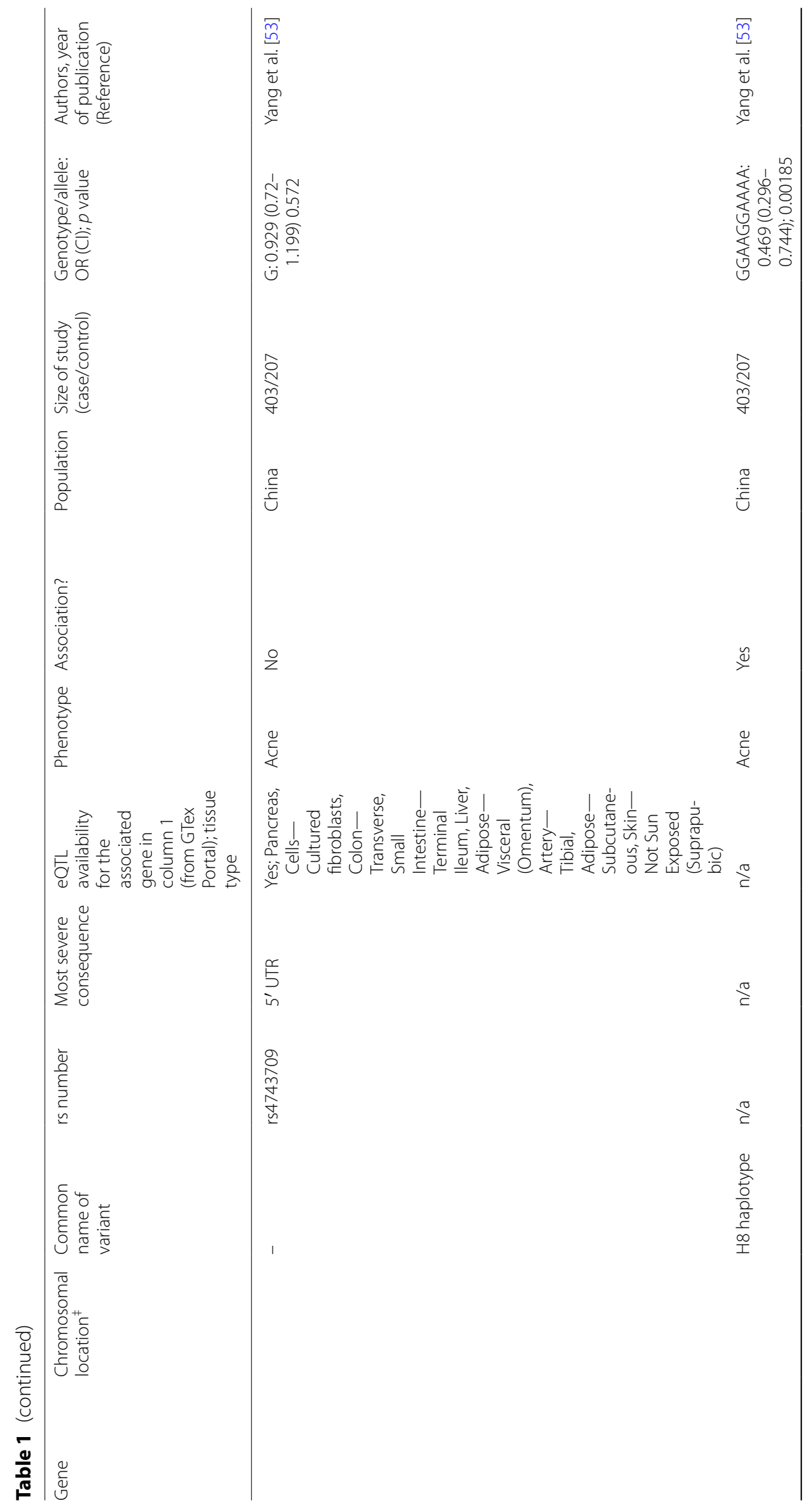




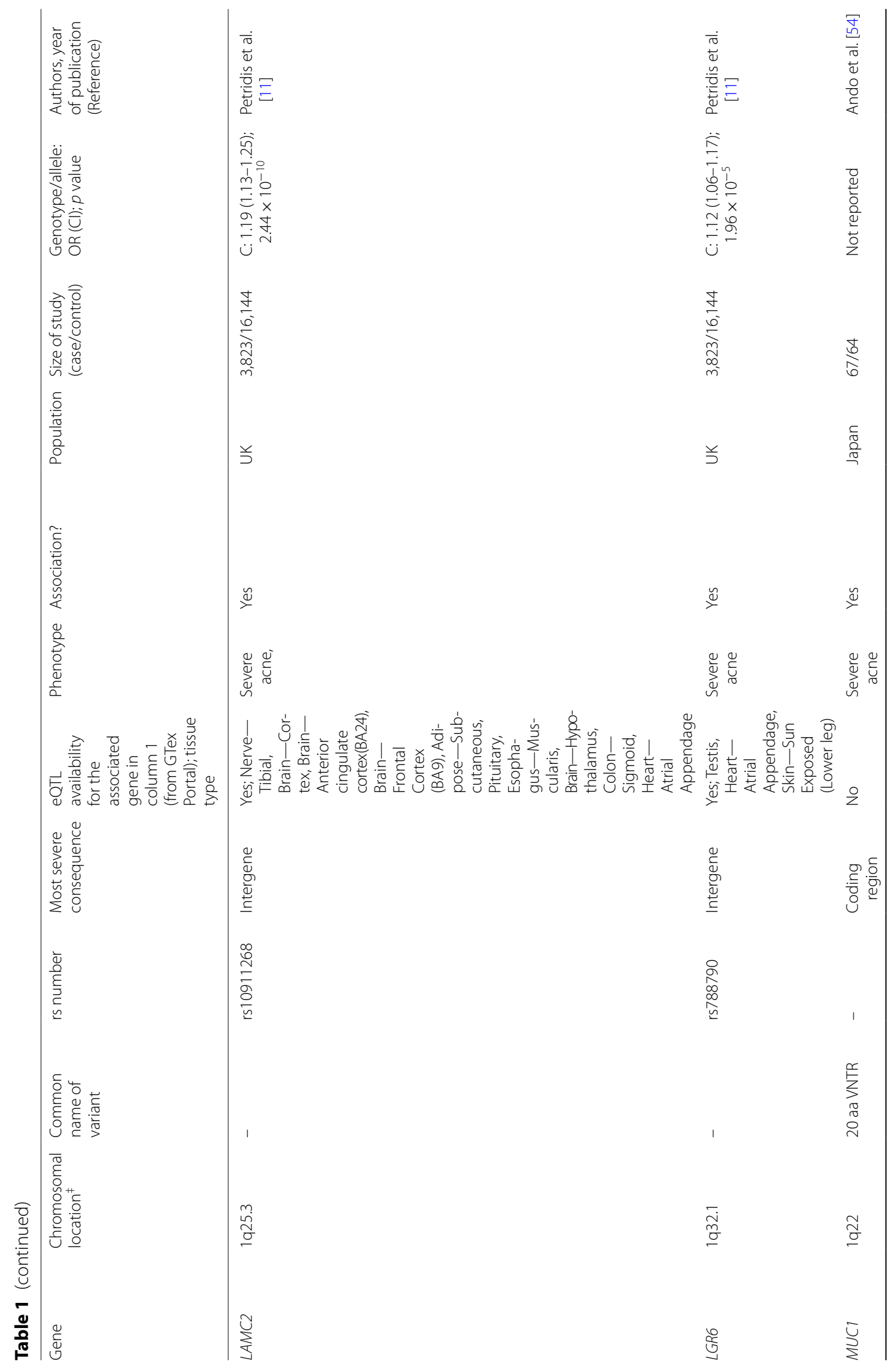




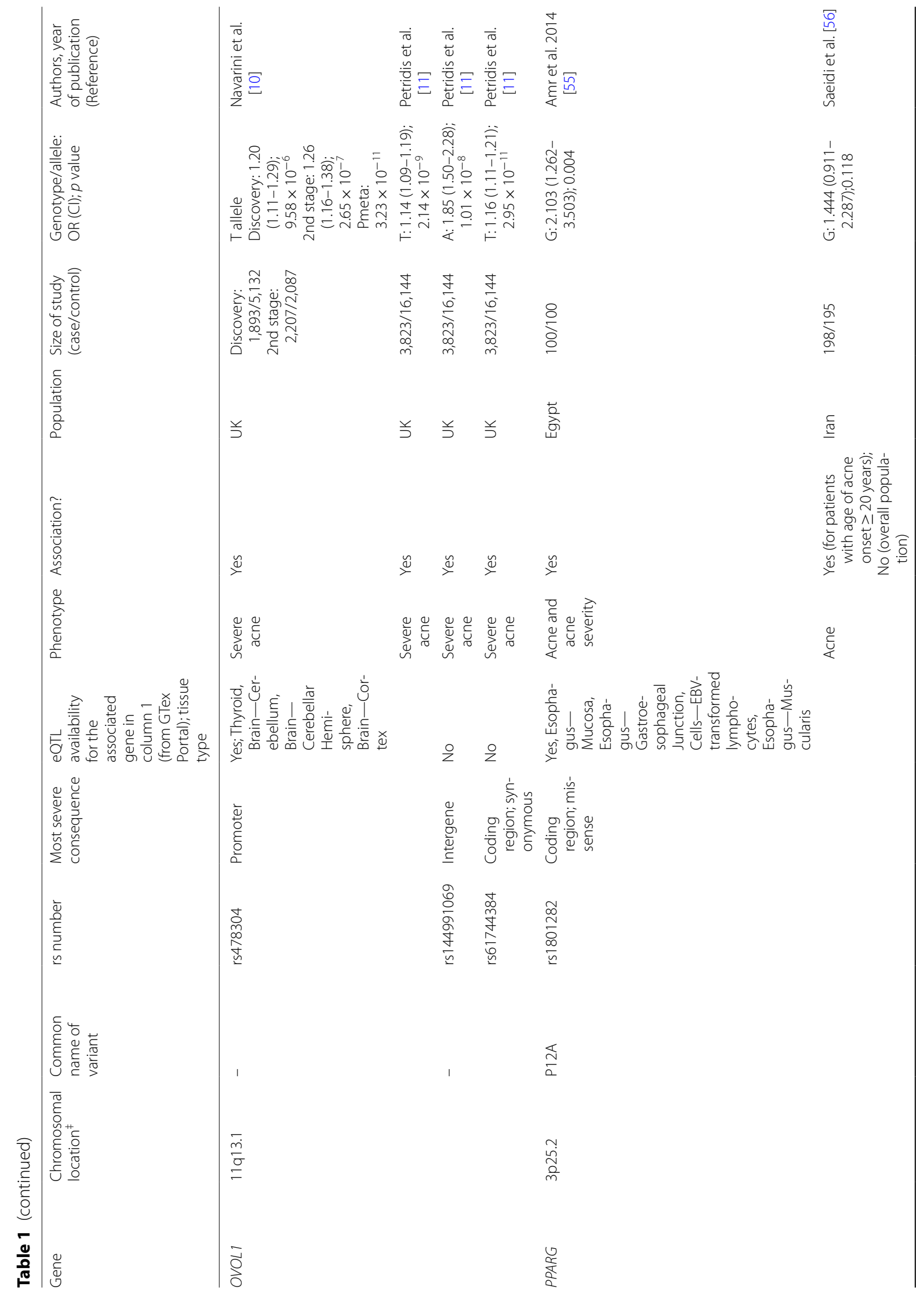




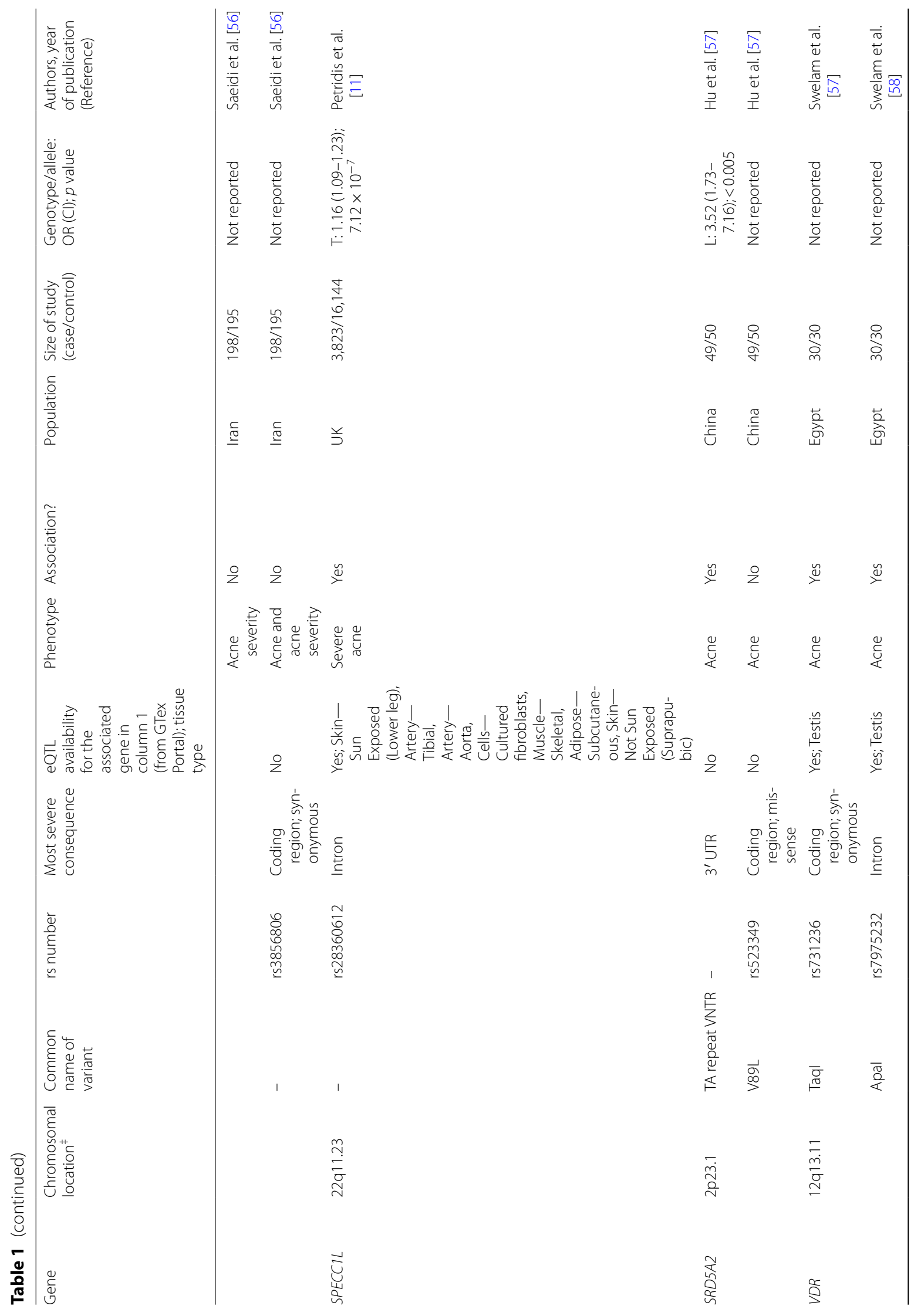




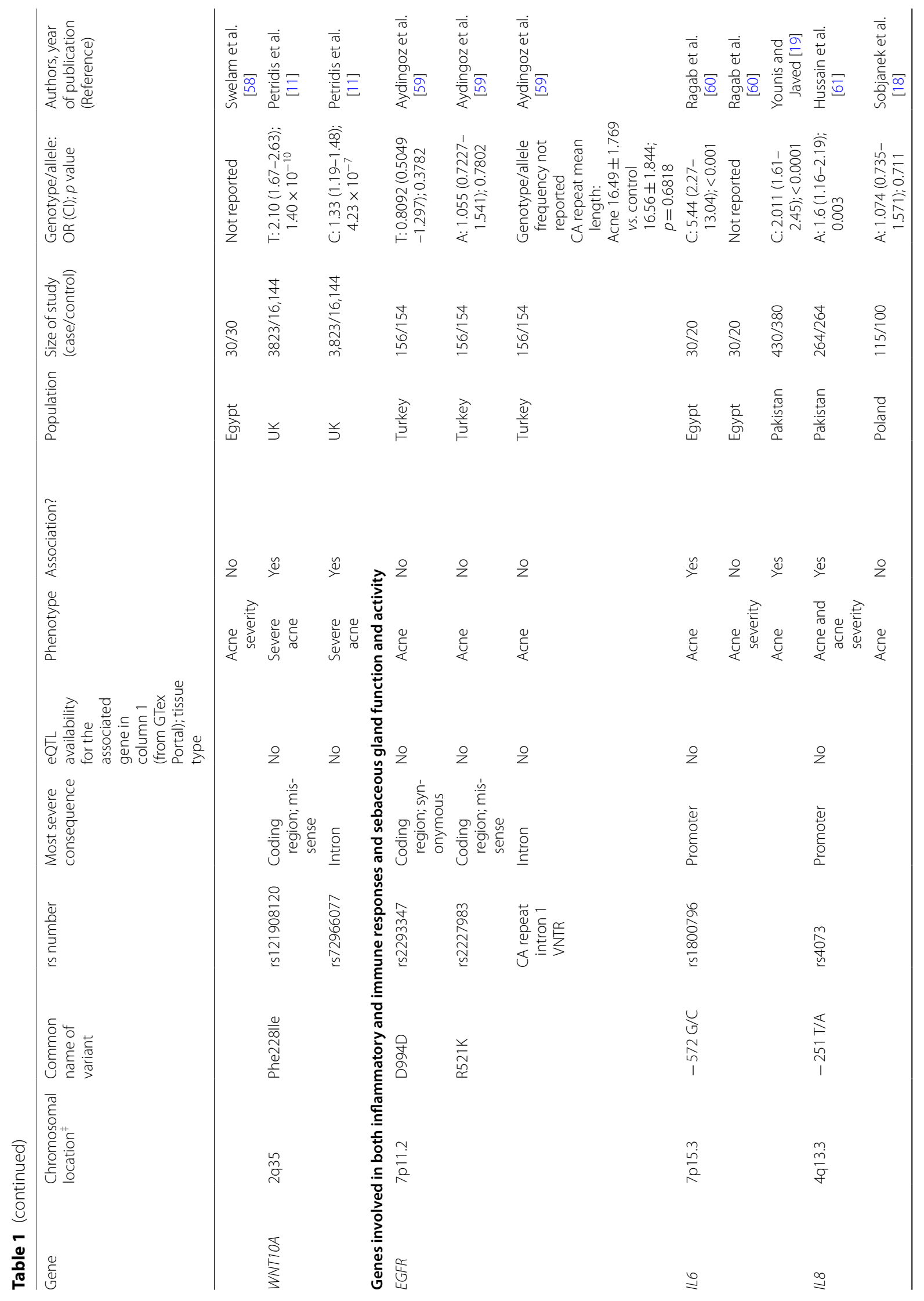




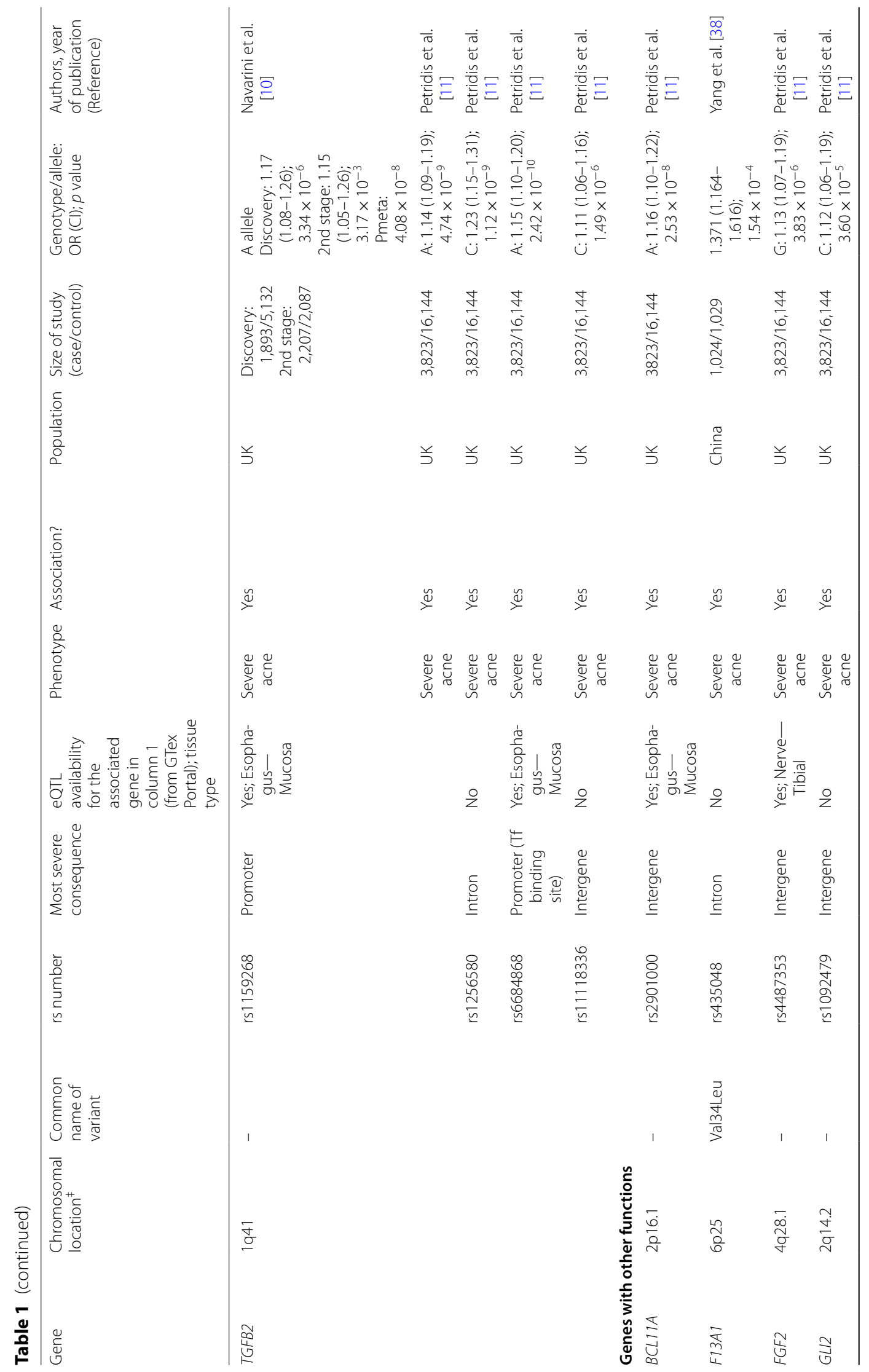




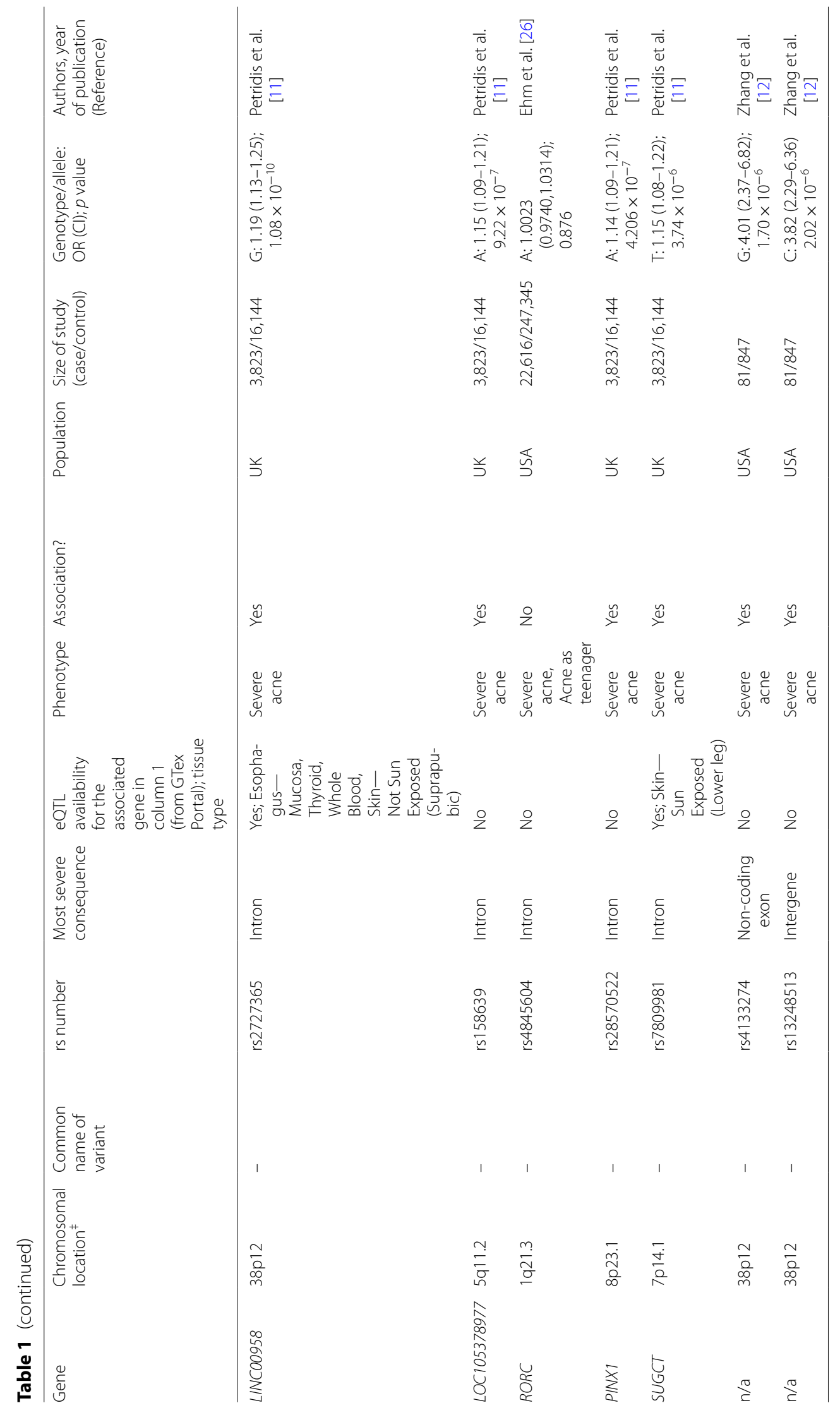




\section{(See figure on next page.)}

Fig. 2 Meta-analysis of TNF SNPs associated with acne presentation and acne severity grades. a Subgroup meta-analysis of association of rs 1800629 with acne presentation among Asians and Caucasians. $\mathbf{b}$ Subgroup meta-analysis of association of rs 1800629 with acne severity among different grades. c Meta-analysis of association of rs 361525 with acne presentation. Only gene variants that were investigated in at least two other previous studies were included in the meta-analysis. Analysis was performed under allele model (minor allele vs. major allele)., i.e. A versus $\mathrm{G}$ for both rs1800629 and rs361525

population [35]. Meta-analysis of these and our study for acne presentation showed that the pooled OR was 0.97 (95\% CI: $0.82-1.11$ ) (Fig. 2a), while a subgroup analysis by ethnicity revealed an OR of 0.98 (95\% CI: 0.82-1.13) and 0.93 (95\% CI: 0.59-1.26) among Asians and Caucasians, respectively. Significant heterogeneity was observed across these reported findings, suggesting these analyzed findings had different study outcomes across each other (all $\mathrm{I}^{2} \geq 50 \%, p<0.05$ ). This heterogeneity also corresponds to the publication bias detected for this SNP. While for acne severity, a subgroup analysis revealed an OR of 0.60 (95\% CI: 0.33-0.86), 1.16 (95\% CI: 0.73-1.58), and 1.09 (95\% CI: 0.55-1.64) among mild, moderate and severe grades, respectively (Fig. 2b). No significant heterogeneity was found for all severity grades $\left(\mathrm{I}^{2}<50 \%\right.$, $p>0.05$ ), suggesting that rs 1800629 A allele carriers had significantly reduced mild acne risk compared with G allele carriers across all populations.

Studies that investigated - 238 SNP (rs361525) showed mixed results. The -238 SNP was significantly associated with acne and acne severity among Pakistanis [33], while no association with acne or with both acne and acne severity was reported among Caucasians in Poland [34] and Hungary/Romania [35]. Meta-analysis of these and our study showed that this SNP was not significantly associated with acne, as the pooled OR was 1.24 (95\% CI: $0.85-1.63)$, with no significant heterogeneity observed $\left(\mathrm{I}^{2}=0 \%, \quad p=0.585 ;\right.$ Fig. 2c). Lastly, TNF-238,-308 and -376 haplotypes did not show association with acne risk [37].

The -857 SNP (rs1799724) was significantly associated with acne and acne severity among Caucasians [12, 35], while -863 and -1031 SNPs were not [34]. In the case of rs1799724, the major $C$ allele exhibited a positive association with acne, whereas the minor $\mathrm{T}$ allele seemed to have a protective effect [35]; consistent with studies on other chronic inflammatory diseases [63]. The C/T base change generates a novel transcription factor binding site (OCT-1) at the promoter region of TNF, immediately next to a pre-existing NF- $\mathrm{kB}$ binding site, resulting in an altered $T N F$ regulation in response to various stimuli [64]. This suggests the general importance of this SNP in regulating TNF expression.

In addition, two studies which investigated the M196R variation in TNFR2 (Tumor Necrosis Factor Receptor 2) found a significant association with acne presentation and severity among Han Chinese [32], but not among Caucasians [12].

\section{Interleukins (IL) and their associated antagonists and receptors}

A frequently studied group of genes involved in inflammation and immune responses is the interleukins (IL) and their associated antagonists and receptors. The interleukin genes studied include $I L 1 A$ (Interleukin-1 $\alpha$ ), IL1B (Interleukin-1 $\beta), I L 4$ (Interleukin-4), IL6 (Interleukin-6), IL8 (Interleukin-8), IL10 (Interleukin-10), IL17A (Interleukin-17A), IL17F (Interleukin-17F), while the antagonists and receptors include IL1RN (Interleukin 1 Receptor Antagonist) and IL4R (Interleukin-4 Receptor), IL17RB (Interleukin-17 Receptor B) and IL23R (Interleukin-23 Receptor).

Several studies found that the $I L 1 A-889$ C/T SNP (rs1800587) was associated with acne among Asian and European populations [18-20] while +4845 G/T SNP only showed association among Caucasians in Hungary/ Romania [21], but not in USA [12]. Meta-analysis of rs1800587 studies and our study showed that this SNP was significantly associated with acne, as the pooled OR was 1.34 (95\% CI: 1.14-1.54), with significant heterogeneity observed $\left(\mathrm{I}^{2}=77.3 \%, p=0.004\right.$; Fig. 3a). Meanwhile, $I L 1 A+4845 \mathrm{G} / \mathrm{T}$ SNP causes an Ala114Ser substitution close to the proteolytic cleavage site of nuclear pre-IL- $\alpha$ $(117 / 118)$ to mature IL- $\alpha$, and might result in enhanced cleavage when the rare $\mathrm{T}$ allele is present $[65,66]$. PreIL- $1 \alpha$ has a predominantly nuclear localization, whereas mature IL- $\alpha$ exhibits a cytoplasmic localization and can be secreted in response to the appropriate signals [67]. Therefore, carriers of the $\mathrm{T}$ allele may have a higher risk of more severe acne symptoms that result from enhanced inflammatory reactions by increased IL- $\alpha$ secretion $[13$, 22].

In contrast, IL $1 B-511 \mathrm{C} / \mathrm{T}, I L 4-590 \mathrm{~T} / \mathrm{C}, I L 10-1082$ A/G SNPs and IL1RN variable number tandem repeats (VNTR) all showed no significant association with acne and/or acne severity in the studied populations [21-24]. Furthermore, a study in Saudi Arabia found that the IL $4 R$ Q551R SNP was significantly associated with acne but not acne severity [23].

Two studies also found a significant association between IL6-572 G/C variants and acne presentation $[19,60]$. Meta-analysis of these and our study showed 


\section{a TNF rs1800629 acne presentation}

OR $(95 \% \mathrm{Cl})$

\%eight

\section{Asian}

Aisha et al., 2016 (Pakistan) [33]

Akoglu et al., 2018 (Turkey) [22]

Al-Shobaili et al., 2012 (Saudi Arabia) [24]

Baz et al., 2008 (Turkey) [36]

Our study, 2020 (Singapore)

Subtotal $\left(l^{2}=71.7 \%, p=0.007\right)$

Caucasian

Grech et al., 2014 (Greece) [37]

Sobjanek et al., 2009 (Poland) [34]

Szabó et al., 2011 (Hungary/Romania) [35]

Subtotal $\left(1^{2}=69.0 \%, p=0.040\right)$

Heterogeneity between groups: $p=0.787$

Overall $\left(I^{2}=66.1 \%, p=0.004\right)$

$1.50(1.07,2.19)$

$0.55(0.28,1.08)$

$0.88(0.64,1.22)$

$1.07(0.86,1.32) \quad 38.03$

\section{b TNF rs1800629 acne severity}

\section{Mild}

Aisha et al., 2016 (Pakistan) [33]

Akoglu et al., 2018 (Turkey) [22]

Al-Shobaili et al., 2012 (Saudi Arabia) [24]

Baz et al., 2008 (Turkey) [36]

Szabo et al., 2011 (Hungary/Romania) [35]

Moderate

Aisha et al., 2016 (Pakistan) [33]

Akoglu et al., 2018 (Turkey) [22]

Al-Shobaili et al., 2012 (Saudi Arabia) [24]

Baz et al., 2008 (Turkey) [36]

Szabó et al., 2011 (Hungary/Romania) [35]

Subtotal $\left(1^{2}=35.4 \%, p=0.185\right)$

Severe

Aisha et al., 2016 (Pakistan) [33]

Akoglu et al., 2018 (Turkey) [22]

Al-Shobaili et al., 2012 (Saudi Arabia) [24]

Baz et al., 2008 (Turkey) [36]

Szabó et al., 2011 (Hungary/Romania) [35]

Subtotal $\left(I^{2}=27.2 \%, p=0.240\right)$

Heterogeneity between groups: $\mathrm{p}=0.045$

Overall $\left(I^{2}=38.7 \%, p=0.063\right)$

$$
-35.2
$$

$0.98(0.82,1.13) \quad 81.65$

OR $(95 \% \mathrm{Cl})$

$0.50(0.28,0.90)$

$0.74(0.23,2.33)$

$0.70(0.33,1.49)$

$6.60(2.74,15.92)$

$1.38(0.57,3.34)$
$0.60(0.33,0.86)$

$2.36(1.09,5.11)$

$0.57(0.17,1.87)$

$1.05(0.58,1.89)$

$3.30(1.49,7.32)$

$1.53(0.91,2.59)$

$1.16(0.73,1.58)$

1.70

12.05

4.60

18.35

00.00

$-35.2$

(2)

C TNF rs361525 acne presentation

$10.33(3.04,35.17)$

$\begin{array}{ll}10.33(3.04,35.17) & 0.02\end{array}$

$\begin{array}{ll}0.64(0.22,1.87) & 6.24 \\ 1.26(0.64,2.45) & 5.17\end{array}$

$1.26(0.64,2.45) \quad 5.17$

$\begin{array}{ll}5.78(2.35,14.20) & 0.12 \\ 1.59(0.75,3.33) & 2.55\end{array}$

$\begin{array}{ll}1.59(0.75,3.33) & 2.55 \\ 1.09(0.55,1.64) & 14.09\end{array}$

$0.80(0.59,1.00) \quad 100.00$

Aisha et al., 2016 (Pakistan) [33]

Sobjanek et al., 2009 (Poland) [34]

Szabó et al., 2011 (Hungary/Romania) [35]

Our study, 2020 (Singapore)

Overall $\left(1^{2}=0.0 \%, p=0.585\right)$

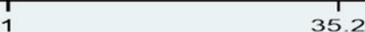

35.2

OR $(95 \% \mathrm{Cl})$

$\%$ Weight

$1.60(1.06,2.44) \quad 31.49$

$1.36(0.47,3.91) \quad 5.07$

$1.34(0.61,2.96) \quad 10.86$

$0.99(0.59,1.66) \quad 52.59$

$1.24(0.85,1.63) \quad 100.00$ 

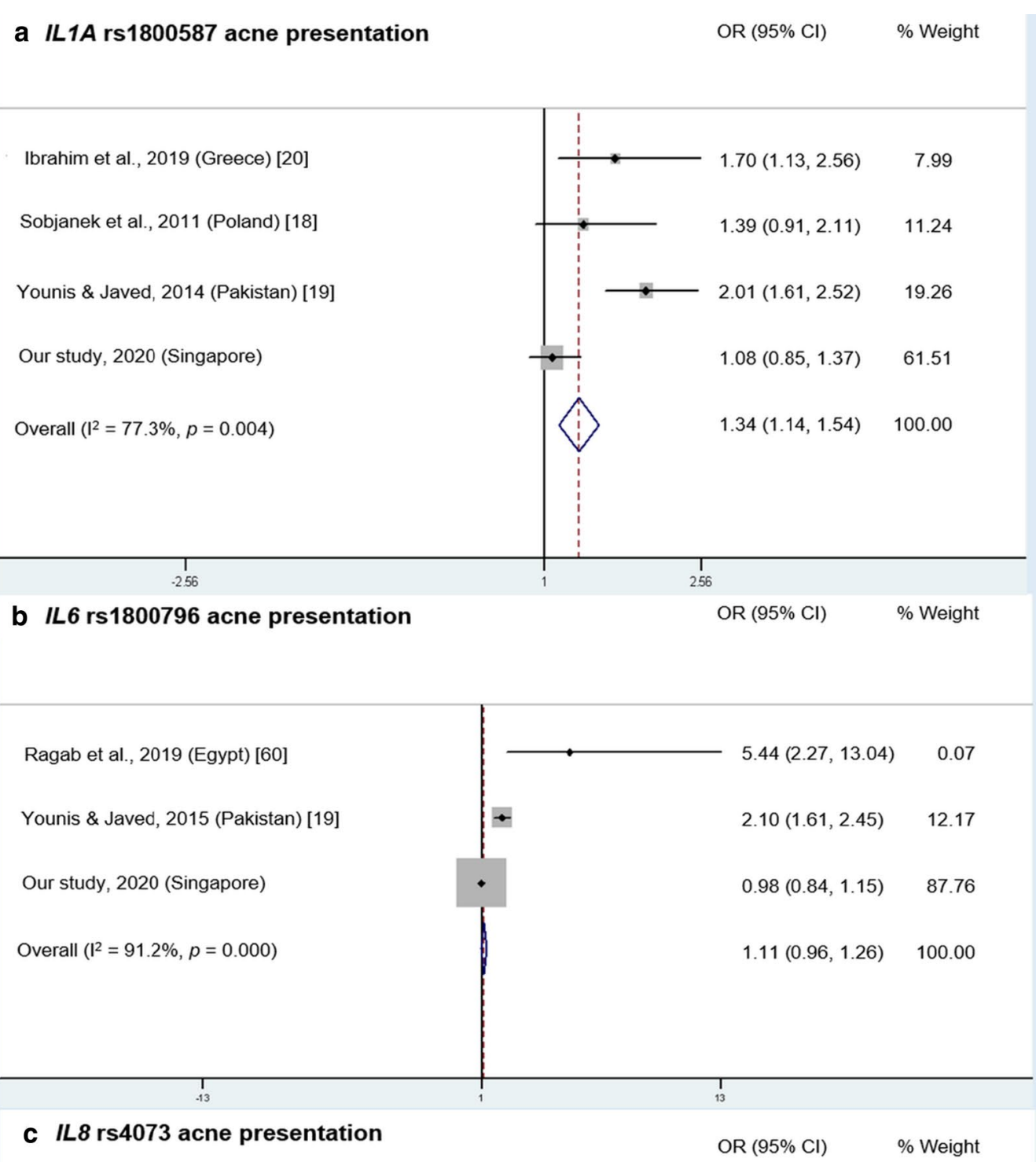

\section{IL8 rs4073 acne presentation}

OR $(95 \% \mathrm{Cl}) \quad \%$ Weight

Hussain et al., 2015 (Pakistan) [61]

Sobjanek et al., 2011 (Poland) [18]

Our study, 2020 (Singapore)

Overall $\left(I^{2}=61.2 \%, p=0.076\right)$

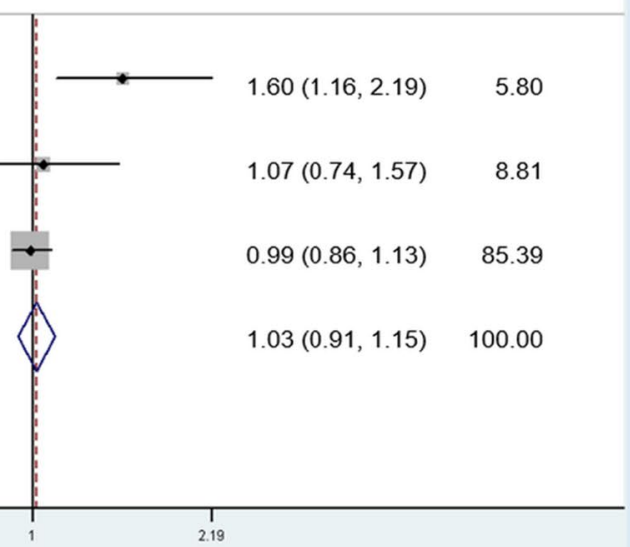

Fig. 3 Meta-analysis of IL SNPS associated with acne presentation. a IL 1A rs1800587. b /L6 rs1800796. c IL8 rs4073. Only gene variants that were investigated in at least two other previous studies were included in the meta-analysis. Analysis was performed under allele model (minor allele vs. major allele), i.e. T versus. C for rs 1800587, C versus. G for rs 1800796 and A versus T for rs 4073 
that this SNP was not significantly associated with acne, as the pooled OR was 1.11 (95\% CI: 0.96-1.26), with significant heterogeneity observed $\left(\mathrm{I}^{2}=91.2 \%, p=0.000\right.$; Fig. 3b). Lastly, IL8 - 251 T/A SNP was found to be significantly associated with acne and acne severity among Pakistanis [61], but not among Polish [18]; meta-analysis of these and our study showed that this SNP was not significantly associated with acne, as the pooled OR was 1.03 (95\% CI: 0.91-1.15), with no significant heterogeneity observed $\left(\mathrm{I}^{2}=61.2 \%, p=0.076\right.$; Fig. $\left.3 \mathrm{c}\right)$.

Lastly, Ehm et al. [26] found that IL17A rs2275913, IL17F rs763780, IL17RB rs1043261 and IL23R rs11209026 all had no significant association with both severe acne and teenage acne.

\section{Toll-like receptor (TLR) family}

Another gene family implicated is the toll-like receptor (TLR) gene family. None of the TLR4 variants (rs4986790 and rs4986791) investigated in the reviewed articles were found to be associated with acne risk [12, 31]. Both of these SNPs change amino acids in the ligand recognition part of the receptor, but most in vitro functional studies suggest that the LPS-induced cytokine response of the Asp299Gly/Thr399Ile haplotype does not differ from that of the wild-type cytokine response [reviewed in [68]]. Nevertheless, there was a study which found increased tumor necrosis factor- $\alpha$ (TNF- $\alpha$ ) cytokine response of the African-exclusive Asp299Gly/wild-type haplotype [69]. Using a subset of genotyping data of 982 acne cases and 846 controls extracted from our existing GWAS database (Additional file 2), we found that out of all the gene variants in this systematic review (Table 1 ), only TLR4 (Additional file 2: Table S2.1) was significantly associated with acne presentation. Specifically, within $2 \mathrm{~kb}$ of this gene, 15 SNPs located in the $3^{\prime}$ UTR region (Additional file 2: Fig. S1), were significantly associated with acne presentation ( $p=0.021222$ for all SNPs; Additional file 2: Table S2.2).

Furthermore, no significant association with acne was found for two TLR2 variants $+2179 \mathrm{C} / \mathrm{T}$ and +2258 G/A among Caucasians [12, 31]. However, the latter SNP was significantly associated with acne and acne severity among Han Chinese [32]. The possible explanation in the discrepancy in the findings is that a highly homologous duplicated segment of exon 3 (harboring the SNP) exists $23 \mathrm{~kb}$ upstream of the TLR2 locus [70]. In vitro data showed that the Arg to Gly change may impair TLR2mediated immune signaling and the expression of various downstream target genes in response to microbial ligands $[71,72]$, suggesting that if this SNP may be a functional one in populations where it is truly present with reasonable frequency.

\section{Other genes}

Other genes and polymorphisms that are likely to influence acne or acne severity by affecting immune and inflammatory responses are described as follows. The reviewed articles reported that RETN (resistin) SNPs $-420 \mathrm{C} / \mathrm{G}$ and $+299 \mathrm{G} / \mathrm{A}$ were significantly associated with the risk of acne and more severe forms of acne $[29,30]$, while the-- $20 /+299$ GA haplotype was significantly associated with the risk of acne [30]. Furthermore, one report found that NLRP3 (NOD-like receptor protein 3) rs10754558, but not rs4612666, was significantly associated with acne risk [73]. Other SNPs that were significantly associated with acne presentation: $A C E$ (angiotensin-converting enzyme) I/D VNTR [17], MMP2 (Matrix metalloprotease 2) rs2285053 [28]; severe acne: $M A P K 11$ (mitogen-activated protein kinase 11) rs144991069, SEMA4B (semaphorin 4B) rs34560261, SELL (selectin L) rs7531806, TGFB2 (transforming growth factor beta 2) rs1256580 [11], TNFRSF1B rs1061622 [32], TRAF3IP2 (TRAF3 Interacting Protein 2) rs33980500 [26]; and teenage acne: TYK2 (tyrosine kinase 2) rs12720356 [26]. Meta-analysis of SELL rs7531806 and TGFB2 rs1256580 SNPs found that the minor alleles posed a significantly increased risk for acne-pooled OR was 1.06 (95\% CI: $1.03-1.09$ ) and 1.11 (95\% CI: $1.07-1.16)$, respectively, albeit with significant heterogeneity observed $\left(\mathrm{I}^{2}=89.4 \%, \quad p=0.000 ; \mathrm{I}^{2}=82.6 \%, p=0.003\right.$, respectively; Fig. 4a, 4b).

In contrast, SNPs that showed no significant association with acne risk, include EGFR (epithelial growth factor receptor) variants rs2293347, rs2227983, CA repeat intron 1 VNTR [59], ITLN1 (Intelectin-1/Omentin) Val109Asp [24], MMP2 (matrix metallopeptidase 2) - $1306 \mathrm{C} / \mathrm{T}$ [27], NLRP3 (NLR family pyrin domain containing 3) rs4612666 [73], and TIMP2 (TIMP metallopeptidase inhibitor 2) $-418 \mathrm{G} / \mathrm{C}[27,28]$. Meta-analysis of TIMP2 rs8179090 also confirmed no significant association with acne risk [pooled OR $=0.96$; $(95 \%$ CI: 0.80-1.12); no significant heterogeneity observed $\left(\mathrm{I}^{2}=0 \%, p=0.437\right)$; Fig. $\left.4 \mathrm{c}\right]$.

\section{Genes and gene variants involved in sebaceous gland function and activity}

Some genes implicated in acne and severe acne risk may influence the function and activity of the sebaceous gland. Two frequently studied gene families that have been implicated are the cytochrome P450 (CYP) gene family and the 3-beta hydroxysteroid dehydrogenase/isomerase (HSD3B) gene family. 


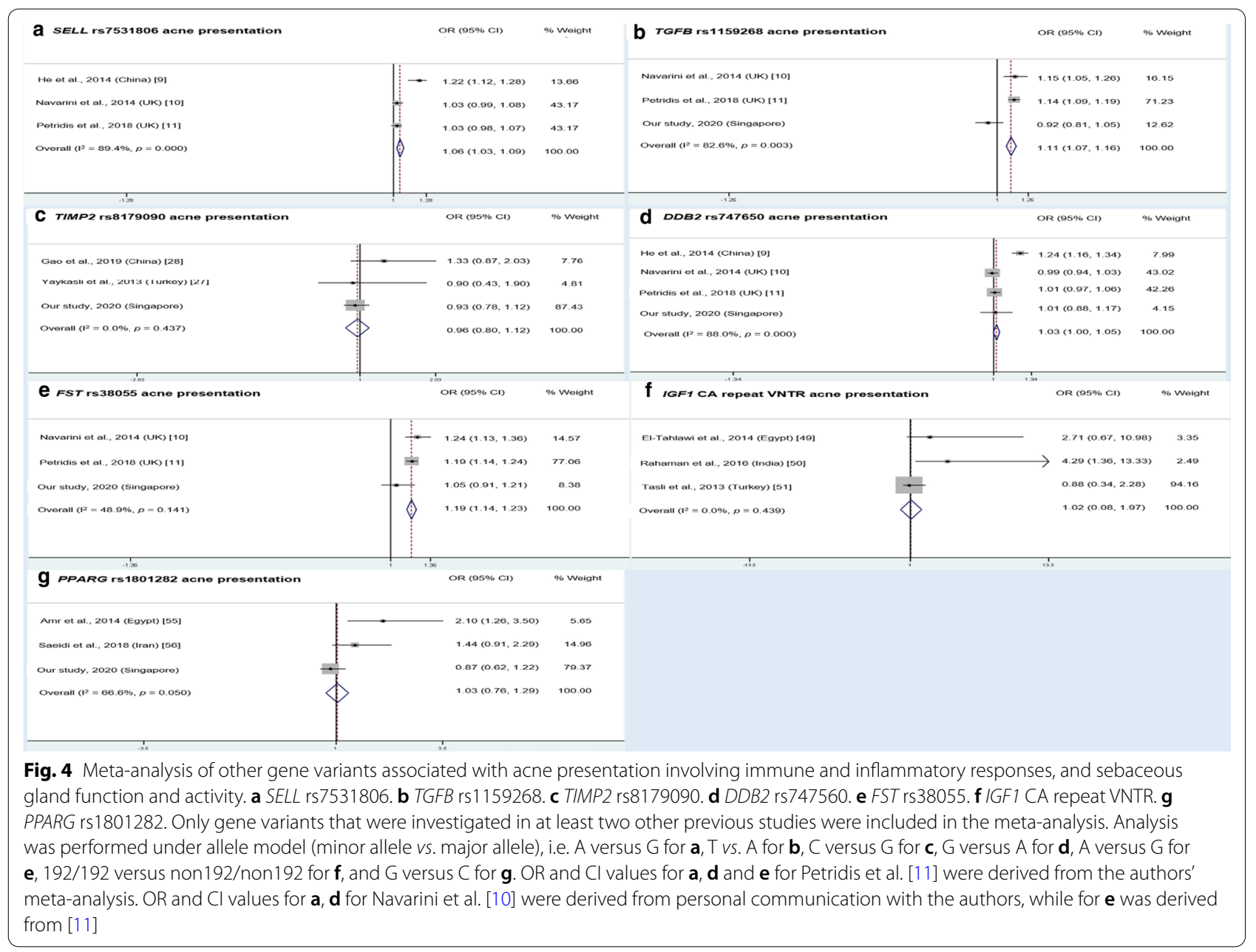

\section{CYP family}

The CYP genes investigated included CYP17 (Cytochrome P450 Family 17 Subfamily A Member 1), CYP19A1 (Cytochrome P450 Family 19 Subfamily A Member 1) and CYP1A1 (Cytochrome P450 Family 1 Subfamily A Member 1).

For CYP17A1, a Chinese study found that the $-34 \mathrm{~T} / \mathrm{C}$ SNP was not significantly associated with both acne in the overall population and acne severity in females, but was significantly associated with acne severity in males, suggesting gender differences in acne severity genetic predisposition [45]. Another CYP17A1 SNP rs743572 was investigated in three studies-two studies reported significant association with acne and acne severity [43, 44], while another did not [12]. Meta-analysis of these and our study for acne presentation showed that this SNP was not significantly associated with acne, as the pooled OR was 1.03 (95\% CI: 0.91-1.15) (Fig. 5a), while a subgroup analysis revealed an OR of 0.95 (95\% CI: 0.68-1.23), 1.08 (95\% CI: $0.76-1.40)$, and 0.59 (95\% CI: 0.40-0.79) among mild, moderate and severe grades, respectively (Fig. 5b). Significant heterogeneity was observed across these reported findings, suggesting these analyzed findings had different study outcomes across each other (all $\mathrm{I}^{2} \geq 50 \%, p<0.05$ ). These heterogeneities also correspond to the publication bias detected for this

(See figure on next page.)

Fig. 5 Meta-analysis of CYP SNPs associated with acne presentation and acne severity grades. a Meta-analysis of association of CYP17A1 rs 743572 with acne presentation. $\mathbf{b}$ Subgroup meta-analysis of association of rs 743572 with acne severity among different grades. c Meta-analysis of association of CYP1A1 rs4646903 with acne presentation. Only gene variants that were investigated in at least two other previous studies were included in the meta-analysis. Analysis was performed under allele model (minor allele vs. major allele)., i.e. T versus C for rs 743572 and C versus $T$ for rs464903 


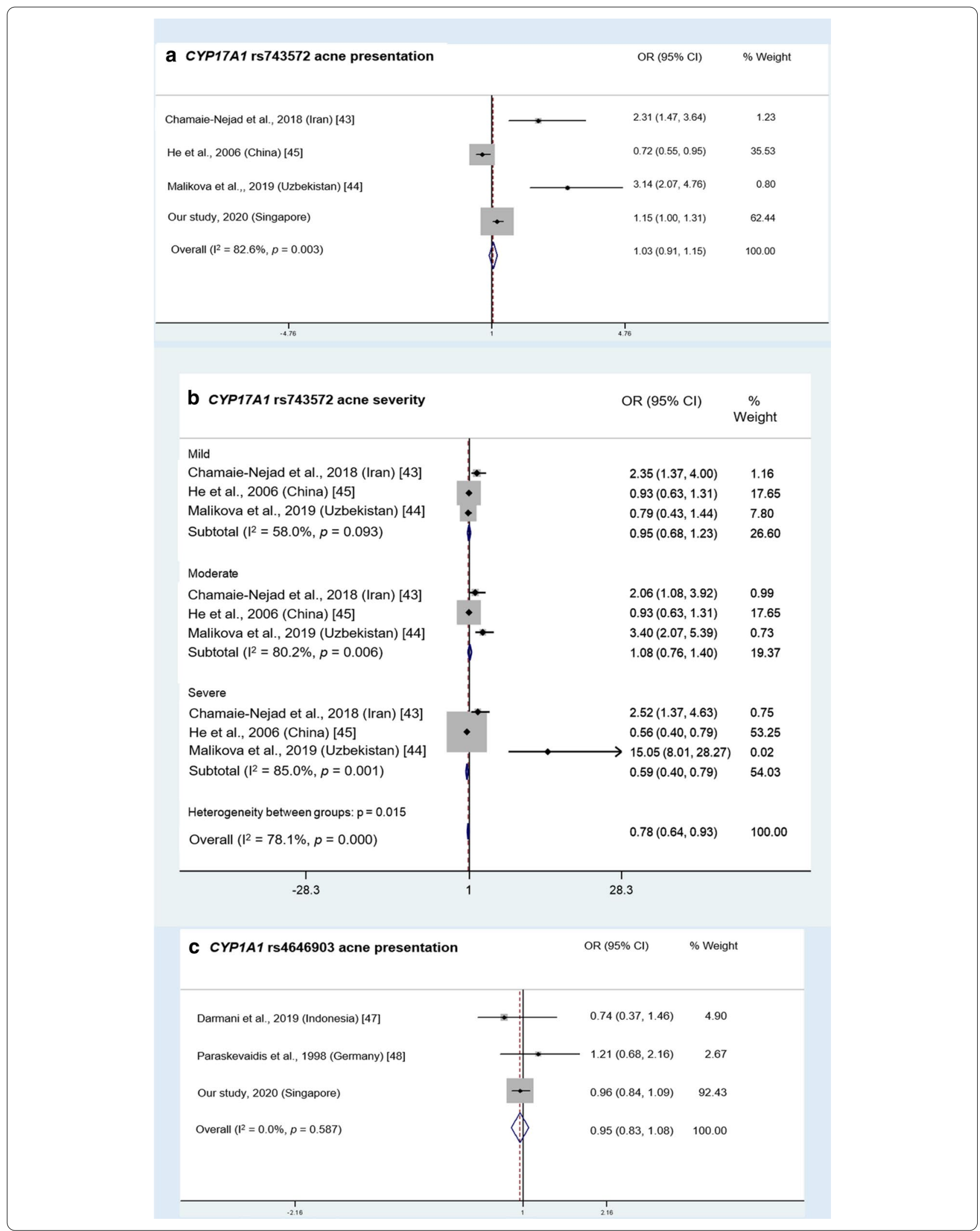


SNP. Although this SNP may affect $C Y P 17$ regulation by creating a putative novel SP1 promoter-binding site [74], in vitro EMSA experiments have so far not showed any evidence on this [75].

In addition, two CYP19A1 SNPs, rs2236722 and rs700518, were significantly associated with acne presentation and severity $[43,46]$. Two CYP1A1 candidate SNPs were also studied where no significant association with acne was found: +4889 A/G SNP in the German population [48] and $+6235 \mathrm{~T} / \mathrm{C}$ SNP (rs4646903) in Indonesian [47], German [48] populations and in our meta-analysis [pooled OR: 0.95, 95\% CI: 0.83, 1.08; no significant heterogeneity observed $\left(\mathrm{I}^{2}=0 \%, p=0.587\right)$; Fig. $\left.5 \mathrm{c}\right]$.

\section{HSD3B family}

Three members of the $3-\beta$ HSD family were investigated in the reviewed studies. A Chinese study found that HSD3B1 (Hydroxy-Delta-5-Steroid Dehydrogenase, 3 Beta- and Steroid Delta-Isomerase 1) rs6428829 and AAT haplotype, and HSD17B3 (Hydroxysteroid 17-Beta Dehydrogenase 3) H8 haplotype were significantly associated with acne risk [53]. In contrast, a study in Egypt found that HSD11B1 rs12086634 variants were associated with acne risk while the relationship between $H S D 11 B 1$ rs846910 variants and acne risk was unclear [52].

\section{Other genes}

Other frequently studied genes thought to influence sebaceous gland function and activity include the androgen receptor $(A R)$, peroxisome proliferator activated receptor gamma (PPARG) and insulin like growth factor 1 (IGF-1) genes. For $A R$, a Chinese study observed that GGN (Gly) repeat VNTR was not significantly associated with acne risk [39]. However, for the CAG (Gln) repeat VNTR, a significant association with acne risk was observed in one study [39] while other studies showed that it was significantly associated with acne and acne severity in males, but not in females [40] and vice versa [41]. This suggests that there may be gender differences in the association between AR CAG repeat VNTR and both acne and acne severity. Biologically, these VNTRs cause variation in the lengths of polyGln and polyGly stretch in the N-terminal domain of AR receptor. The variations in repeat lengths in both VNTRs have been shown to be associated with subtle modulations of $A R$ expression, resulting in the modified transcriptional activity of various downstream targets. The transcriptional activity of $A R$ is inversely correlated with number of the polyGln repeat length; shorter alleles exhibit greatest activity [76-78]. Furthermore, in vitro results suggest that acne patients carrying fewer CAG repeats may exhibit a higher AR mRNA and protein expression, leading to higher sensitivity to androgens than in control individuals [79].
For PPARG, a study in Iran found that rs3856806 and rs1801282 SNPs were not associated with acne and acne severity in the overall population [56]. However, the study found that rs1801282 was associated with acne risk in a subset of patients who developed acne at the age of 20 or older. Another study observed that the Pro/ Ala genotype of rs1801282 appeared to be protective for acne and more severe acne [55]. However, our metaanalysis revealed that the $\mathrm{rs} 1801282 \mathrm{G}$ allele do not pose any increased/decreased risk for acne [pooled OR: 1.03, 95\% CI: 0.76, 1.29; significant heterogeneity observed $\left(\mathrm{I}^{2}=66.6 \%, p=0.050\right) ;$ Fig. $\left.4 \mathrm{~g}\right]$. This heterogeneity also corresponds to the publication bias detected for this SNP. Similarly, with reference to IGF1, the length of CA repeats was found to be significantly associated with acne risk only [49], and the risk of both acne and more severe forms of acne $[50,51]$. However, our meta-analysis revealed that the IGF1 VNTR 192/192 genotype do not pose any increased/decreased risk for acne [pooled OR: 1.02, 95\% CI: 0.08, 1.97; no significant heterogeneity observed $\left(\mathrm{I}^{2}=0 \%, p=0.439\right)$; Fig. $\left.4 \mathrm{f}\right]$.

Gene variants that were significantly associated with severe acne risk include: $D D B 2$ (damage specific DNA binding protein 2) rs747650 and rs1060573 [10], MUC1 (mucin 1) 20aa VNTR [54], FST (follistatin) rs629725, LAMC2 (laminin subunit gamma 2) rs10911268, LGR6 (leucine rich repeat containing G protein-coupled receptor 6) rs788790, OVOL1 (ovo like transcriptional repressor 1) rs144991069, SPECC1L (sperm antigen with calponin homology and coiled-coil domains 1 like) rs28360612, and WNT10A (Wnt family member 10A) rs121908120 [11]. Our meta-analysis revealed that the FST rs629725 A allele poses a significantly modest increased risk for acne [pooled OR: 1.19, 95\% CI: 1.14, 1.23; no significant heterogeneity observed $\left(\mathrm{I}^{2}=48.9 \%\right.$, $p=0.141$ ); Fig. 4e], while the $D D B 2$ rs747650 G allele also poses a negligible increased risk for acne [pooled OR: 1.03 (95\% CI: 1.00, 1.05), albeit with significant heterogeneity observed $\left(\mathrm{I}^{2}=88.0 \%, p=0.000\right)$; Fig. $\left.4 \mathrm{~d}\right]$.

In addition, the following variants were significantly associated with acne risk: $A D H 7$ (alcohol dehydrogenase 7) rs1154469 [38], SRD5A2 (steroid 5 alpha-reductase 2) TA repeat VNTR [57] and VDR (vitamin D receptor) rs731236 and rs7975232 [58]. However, no significant association emerged between SRD5A2 V89L SNP and acne risk [57]. All these genes have been implicated in sebaceous gland function and activity.

\section{Discussion}

Figure 6 summarizes the acne-implicated genes and their potential biological functions in the pathogenesis of acne. These biological functions are also part of the top DAVID functional annotation clusters, as analyzed earlier. 


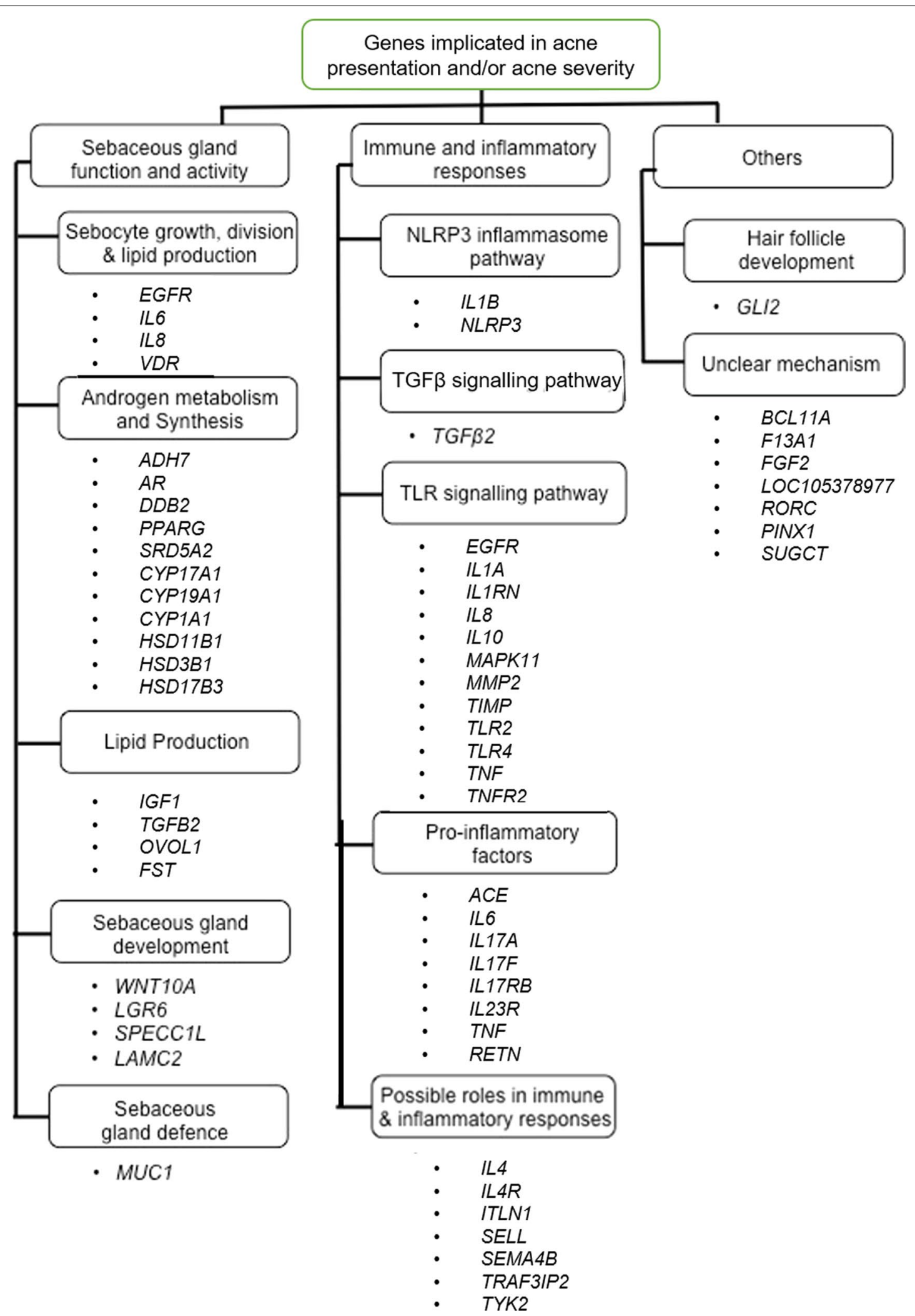

Fig. 6 Flowchart depicting potential mechanisms by which genes implicated in the reviewed studies may influence the risk of acne presentation or acne severity 
Notably, some of these genes have overlapping functions. The following parts will further discuss how these acne-implicated genes play plausible roles in the biological pathways influencing inflammation, sebaceous gland function and activity.

\section{Immune and inflammatory responses}

A contributing factor to the pathogenesis of acne is $C$. acnes, a species of bacteria commonly found in pilosebaceous units that is thought to promote the development of acne lesions [80]. Studies suggest that $C$. acnes can activate the NLRP3 inflammasome pathway, eventually resulting in elevated IL-1 $\beta$ levels and contributing to the pathogenesis of acne [81]. In addition, TGF $\beta$ may not only have roles in sebocyte lipid synthesis, but may also regulate immune responses against $C$. acnes. Furthermore, $C$. acnes can be recognized by pattern recognition receptors such as TLR2 and TLR4, which mount immune responses against the bacteria [80], thus influencing acne development. Upon recognizing C. acnes, TLRs can activate cellular components such as TNF and IL-1A, which in turn activate chemokines such as IL-8, IL-10 and downstream components that eventually promote inflammation [13, 24]. IL-1A activity may also be modulated by IL1RN [14].

Furthermore, TNF can interact with its receptors, such as TNFR2, activating intracellular signaling cascades. These cascades can activate MAPKs such as MAPK11 that upregulate the expression of pro-inflammatory mediators, and also activate matrix MMPs such as MMP-2 to bring about tissue remodeling [82]. MMP activity is regulated by TIMPs; altering the balance of MMP and TIMP activity may contribute to acne development [27]. Similarly, IL-6 (which could be stimulated by IL17A, IL17F and ACE) is reported play a role in modulating host defense mechanisms [14] and inflammation [83].

Pro-inflammatory factors TNF and IL-6 also have roles in modulating RETN transcription and translation. Studies demonstrate a bidirectional relationship between resistin and TNF and IL-6: TNF and IL-6 not only modulate resistin expression but their activity is in turn modulated by resistin levels [83]. Variation in any of these genes can affect their expression, function or activity, which may predispose individuals to acne or severe acne.

EGF/EGFR signaling plays an important role in the regulation of inflammation by inhibiting proinflammatory cytokines including IL- $1 \alpha$, IL- 8 and TNF- $\alpha$ in C. acnes stimulated epidermal keratinocytes [84].

While the specific roles of IL-4 and IL-4R in the pathogenesis of acne are unclear, these proteins are known to play a role in inflammatory responses. Thus it is hypothesized that IL-4 and IL-4R are involved in the inflammatory processes associated with acne [23]. In addition, studies have shown that adipokines secreted by adipocytes may play a role in inflammation associated with acne [25]. The adipokine omentin may thus influence inflammatory processes that contribute to the pathogenesis of acne, such as by preventing inflammation caused by TNF [25]. Similarly, L-selectin is expressed in certain classes of immune cells and plays a role in immune cell invasion of inflamed tissue [9]. Evidence suggests that SELL, which encodes L-selectin, may contribute to inflammatory processes associated with more severe acne [14]. In addition, while the role of SEMA4B in acne pathogenesis is uncertain, it is known to be involved in immune responses and downregulates the secretion of IL-4 and IL-6 in basophils [85]. Thus, it is possible that SEMA4B may also play a role in acnerelated immune processes.

Finally, two recent bioinformatics studies using gene expression data of the lesional and nonlesional skin of acne patients from the NCBI Gene Expression Omnibus found 12 top upregulated differentially expressed genes (DEGs) involved in immune and inflammatory responses, namely FPR2, ITGB2, CXCL8, C3AR1, CXCL1, FCER1G, LILRB2, PTPRC, SAA1, CCR2, ICAM1, and FPR1 [86, 87]. Specifically, the putative pathways involved in acne pathogenesis include chemokine signaling, cytokinecytokine receptor interaction, and Fc gamma R-mediated phagocytosis [86, 87]. Of note, neither of the variants in these genes have been investigated in candidate gene studies nor were picked up by GWAS for association with acne presentation and severity, thus warrants future investigation.

\section{Sebaceous gland function and activity}

Sebaceous glands, which are involved in the biosynthesis and secretion of sebum, are present on almost the entire body surface, and particularly on the face [88]. Changes in the activity of these glands may lead to changes in skin physiology and have been implicated in the pathogenesis of acne. Increased sebaceous gland activity can result in higher sebum levels, which may hamper normal cellular processes in the skin and eventually lead to the development of acne lesions [88].

Some of the genes found to be associated with acne and acne severity in this review may have roles in the sebaceous gland function and activity, and thus variations in these genes may affect cell signaling and functioning in sebaceous glands, thus contributing to acne development or exacerbating acne. One cell-signaling pathway in sebaceous gland cells (sebocytes) is the VDR pathway. Sebocytes have been reported to express VDR, and studies have shown that VDR activation affects sebocyte growth and division, lipid production and levels of ILs, such as 
IL-6 and IL-8 [89]. Thus, variants in VDR, IL6 and IL8 may affect sebaceous gland function and contribute to acne development or exacerbation.

Two other pathways, the AR and PPAR signaling pathways, may also regulate sebocyte function and activity. Sebocytes have important functions in androgen metabolism, and high androgen levels can upregulate the activity of sebocytes. The effects of androgens on the sebaceous gland are thought to be mediated via AR and PPAR signaling pathways [88]. AR activity may, in turn, be regulated by $D D B 2$. The protein encoded by $D D B 2$ facilitates interactions between $A R$ and a complex responsible for targeting AR for ubiquitination and degradation [14]. In addition, variations in genes involved in androgen synthesis can affect androgen levels and thus influence sebocyte activity. The gene SRD5A2 [57], some members of the $C Y P$ gene family, such as CYP17A1 [13], and some members of the $H S D$ gene family encode enzymes that have roles in androgen synthesis [53]. For example, the enzymes encoded by $H S D 3 B 1$ and $H S D 17 B 3$ are involved in the biosynthesis of testosterone [53].

In addition, variations in genes such as IGF1 and TGFB are suggested to influence the production of lipids in sebocytes, and may contribute to acne development [14]. Notably, dietary variables such as intake of fish, fruits and vegetables were suggested to influence acne and severe acne risk by modulating IGF-1 levels, showing a possible interaction between genetic factors and modifiable risk factors [90]. In addition, the activity of the TGF $\beta$ signaling pathway is regulated by the transcription factor OVOL1 and the protein follistatin (encoded by FST), thus variations in these genes may influence sebocyte lipid synthesis and thus play a part in acne development and exacerbation [14]. Navarini et al. [10] also revealed that transcript levels of TGFB2 and OVOL1 were significantly decreased in fresh inflammatory acne papules compared to normal skin. $M U C 1$ is another gene expressed in sebaceous glands and it encodes for a glycoprotein that may be involved in inhibiting the adhesion of bacteria onto the skin, including the acne-causing bacteria $C$. acnes [54]. Variations in MUC1 may influence the anti-bacterial properties of the glycoprotein, thus influencing acne development.

Furthermore, reports have suggested that some genes implicated in the pathogenesis of acne may be involved in the development of sebaceous glands [91]. One of these genes is WNT10A. WNT10A activity can influence sebum production in the sebaceous gland [11] and may also regulate the differentiation of progenitors to form sebocytes [91]. Thus, changes in Wnt signaling may affect the normal development and functioning of the sebaceous gland and in turn, the risk of acne or severe acne. Wnt signaling is regulated by $L G R 6$, and high $L G R 6$ expression can inhibit sebaceous progenitor differentiation [91]. SPECC1L is also reported to be a component of the Wnt signaling pathway [92] and may be implicated in acne development. Another gene involved in the development of sebaceous glands is $L A M C 2$, which facilitates the migration of sebaceous gland progenitor cells to the site of the gland [91]. Variations in these genes can affect sebaceous gland development, contributing to acne development and exacerbation.

Recently, $A D H 7$ rs1154469 has been identified as a novel susceptibility locus for severe acne among Han Chinese [38]. The most active enzyme encoded by this gene is retinol dehydrogenase; thus it may participate in the synthesis of retinoic acid. Retinoic acid is a retinoid which acts to normalize desquamation within the sebaceous follicles that leads to obstruction of the pilosebaceous canal as seen in acne, by reducing keratinocyte proliferation and promoting differentiation [93].

Notably, environments with high sebum levels favor the growth of $C$. acnes and promote the colonization of pilosebaceous units by $C$. acnes [94]. This suggests a link between the two implicated pathways: changes in the sebaceous gland that lead to increased sebum production may promote $C$. acnes infection, triggering inflammatory and immune responses that contribute to acne pathogenesis.

\section{Other genes and potential pathways implicated in acne}

The rest of the genes identified in the reviewed articles were not implicated in inflammation, immune responses or sebaceous gland function and activity. The genes and SNPs significantly associated with severe acne found by Petridis et al. [11] were: BCL11A (BAF chromatin remodeling complex subunit BCL11A) rs2901000, FGF2 (fibroblast growth factor 2) rs4487353, GLI2 (GLI family zinc finger 2) rs1092479, LOC105378977 rs158639, PINX1 (PIN2 (TERF1) interacting telomerase inhibitor 1) rs 28570522 and $S U G C T$ (succinyl-CoA:glutarate-CoA transferase) rs7809981; and by Yang et al. [38]: F13A1 (Coagulation Factor XIII A Chain) rs435048. Furthermore, a few SNPs that were not located within a gene were investigated in the reviewed studies. The SNPs rs2727365, rs4133274 and rs13248513 SNPs showed a significant association with severe acne risk [11, 12]; the mechanism(s) by which variations at these polymorphisms influence severe acne risk are unclear.

It is also unclear how PINX1, which has functions in telomere length maintenance and chromosome stability [95]; F13A1, which encodes coagulation factor XIII, the last zymogen to become activated in the blood coagulation cascade and a transglutaminase enzyme [96]; $B C L 11 A$, a transcription factor involved in hematopoietic development [97]; FGF2, which is involved in processes 
that contribute to scar formation and wound healing [11]; and SUGCT, which encodes an enzyme that converts glutarate to glutaryl-CoA [98] may influence the pathogenesis of acne.

Genes implicated in acne presentation and severity may influence the pathogenesis of acne through mechanisms other than altering sebaceous gland function or inflammatory and immune responses. For instance, the transcription factor GLI2 regulates the expression of sonic hedgehog (Shh), a component of signaling pathways that influence the development of hair follicles [99]. A previous study reported that several genes involved in hair follicle development were implicated in severe acne risk, suggesting that this pathway may contribute to the pathogenesis of acne [11].

\section{Conclusions}

The reviewed papers reported on genes and their variants associated with the risk of acne presentation and severity. However, the results of different studies show inconsistencies, with some studies reporting that a particular variant increases the risk, while others did not. Out of the 51 studies reviewed, only five (including ours) were GWAS while others where candidate gene studies. Hence, we acknowledge the poor reproducibility of association studies, which could be attributed to factors such as insufficient availability of genetic markers, inadequate handling of population structure, lack of statistical power due to low sample size, improper control of multiple testing and extensive publication bias [reviewed in [100]]. Furthermore, it is also possible that rather than particular SNPs, it is the haplotype of multiple SNPs or changes in gene expression or function that is associated with acne presentation or severity. Rather than considering the impact of individual variants on acne presentation or severity, it may be more helpful to consider the gene as a functional unit and to understand the effects of altered gene function on acne presentation and severity.

In conclusion, this review summarizes the literature on candidate genes implicated in the risk of acne presentation and severity and possible mechanisms by which these genes may affect acne pathogenesis. Notably, a large majority of the candidate genes identified are suggested to have roles in the function and activity of sebaceous glands or immune and inflammatory responses-in line with the literature that describes acne as a chronic inflammatory disease of the pilosebaceous unit. Understanding the genetic susceptibility factors and biological pathways involved in the pathogenesis of acne will help us to gain insights into developing effective acne treatments.

\section{Abbreviations}

ACE: Angiotensin-converting enzyme; ADH7: Alcohol dehydrogenase 7; AR: Androgen receptor; BCL11A: BAF chromatin remodeling complex subunit BCL11A; Cl: Confidence intervals; CYP17: Cytochrome P450 family 17 subfamily A member 1; CYP19A1: Cytochrome P450 family 19 subfamily A member 1; CYP1A1: Cytochrome P450 family 1 subfamily A member 1; DDB2: Damage specific DNA binding protein 2; EGFR: Epithelial growth factor receptor; F13A1: Coagulation factor XIII A chain; FGF2: Fibroblast growth factor 2; FST: Follistatin; GLI2: GLI family zinc finger 2; GWAS: Genome-wide association study; HSD17B3: Hydroxysteroid 17-beta dehydrogenase; 3HSD3B1: Hydroxy-delta5-steroid dehydrogenase, 3 beta- and steroid delta-isomerase; HWE: HardyWeinberg equilibrium; IGF-1: Insulin like growth factor 1; IL10: Interleukin-10; IL17A: Interleukin-17A; IL17F: Interleukin-17F; IL17RB: Interleukin-17 receptor B; IL1A: Interleukin-1 a; IL1B: Interleukin-1 13; IL1RN: Interleukin 1 receptor antagonist; IL23R: Interleukin-23 receptor; IL4: Interleukin-4; IL4R: Interleukin-4 receptor; IL6: Interleukin-6; IL8: Interleukin-8; ITLN1: Intelectin-1/omentin); LAMC2: Laminin subunit gamma 2; LGR6: Leucine rich repeat containing G protein-coupled receptor 6; MAPK: Mitogen-activated protein kinase; MAPK1 1 : Mitogen-activated protein kinase 11; MMP-2: Matrix metallopeptidase 2; MMP2: Matrix metalloprotease 2; MUC1: Mucin 1; NLRP3: NLR family pyrin domain containing 3; NLRP3: NOD-like receptor protein 3; OR: Odds ratio; OVOL1: Ovo like transcriptional repressor 1; PINX1: PIN2 (TERF1) interacting telomerase inhibitor 1; PPARG: Peroxisome proliferator activated receptor gamma; RETN: Resistin; SELL: Selectin L; SEMA4B: Semaphorin 4B; SNP: Single nucleotide polymorphism; SPECC1L: Sperm antigen with calponin homology and coiled-coil domains 1 like; SRD5A2: Steroid 5 alpha-reductase 2; SUGCT : Succinyl-CoA:glutarate-CoA transferase; TGFB2: Transforming growth factor beta 2; TIMP2: TIMP metallopeptidase inhibitor 2; TLR2: Toll-like receptor 2; TLR4: Toll-like receptor 4; TNF: Tumor necrosis factor; TNFR2: Tumor necrosis factor receptor 2; TRAF3IP2: TRAF3 interacting protein 2; TYK2: Tyrosine kinase 2; VDR: Vitamin D receptor; WNT10A: Wnt family member 10A.

\section{Supplementary Information}

The online version contains supplementary material available at https://doi. org/10.1186/s12920-021-00953-8.

\section{Additional file 1: Table S1. PRISMA Checklists. \\ Additional file 2: Table S2.1. Comparison of the genes associated with acne in the genetics review and the genes associated with acne using data extracted from our existing Singapore GWAS database; Table S2.2. SNPS in TLR4 that were significantly associated with acne using data extracted from our existing Singapore GWAS database. Figure S1. Posi- tions of the SNPs significantly associated with acne using data extracted from our existing Singapore GWAS database with reference to the location of TLR4. \\ Additional file 3: Figure S2. Gene ontology analysis/network analysis was performed using the online Database for Annotation, Visualization and Integrated Discovery (DAVID) v6.8 software; Figure S3. Assessment of publication bias using Begg's funnel plots and Egger's test for the SNPs included in the meta-analysis.}

\section{Acknowledgements}

We would like to thank all participants and their family members for willing to participate in the larger GWAS study where the acne case control genotyping data were extracted from, and all authors who have contributed to the studies that we have reviewed.

\section{Authors' contributions}

F.T.C. conceived and supervised the current review study. A.H.S.H and Y.-H.S. conducted the literature review process, analysed the data, and wrote the manuscript. Y.Y.S. and Y.T.N. recruited participants for the GWAS study and analysed the acne case control genotyping data extracted from this database. All authors reviewed and approved the manuscript.

\section{Funding}

F.T.C. has received research support from the the Singapore Ministry of Education Academic Research Fund, Singapore Immunology Network, National 
Medical Research Council (NMRC) (Singapore) and the Agency for Science Technology and Research (A*STAR) (Singapore); Grant Numbers: N-154-000038-001; R-154-000-404-112; R-154-000-553-112; R-154-000-565-112; R-154000-630-112; R-154-000-A08-592; R-154-000-A27-597; BMRC/01/1/21/18/077; BMRC/04/1/21/19/315; SlgN-06-006; SlgN-08-020; NMRC/1150/2008, and $\mathrm{H17/01/a0/008}$. The funding agencies had no role in the study design, data collection and analysis, decision to publish, or preparation of the manuscript.

\section{Availability of data and materials}

All data used and included in this study are available from the corresponding author (F.T.C.).

\section{Declarations}

\section{Ethics approval and consent to participate}

Not applicable.

\section{Consent for publication}

Not applicable.

\section{Competing interests}

The authors declare that they have no competing interests.

Received: 2 November 2020 Accepted: 29 March 2021

Published online: 13 April 2021

\section{References}

1. Williams HC, Dellavalle RP, Garner S. Acne vulgaris. The Lancet. 2012;379(9813):361-72.

2. Mahto A. Acne vulgaris. Medicine (Baltimore). 2017;45(6):386-9.

3. Motley RJ, Finlay AY. How much disability is caused by acne? Clin Exp Dermatol. 1989;14(3):194-8.

4. Cunliffe WJ. Acne and unemployment. Br J Dermatol. 1986;115(3):386-386.

5. Heng AHS, Chew FT. Systematic review of the epidemiology of acne vulgaris. Sci Rep. 2020;10(1):5754.

6. Bataille V, Snieder H, MacGregor AJ, Sasieni P, Spector TD. The influence of genetics and environmental factors in the pathogenesis of acne: a twin study of acne in women. J Invest Dermatol. 2002;119(6):1317-22.

7. Xu S, Wang H, Fan X, Sun L, Yang S, Wang P, et al. The familial risk of acne vulgaris in Chinese Hans? A case-control study. J Eur Acad Dermatol Venereol. 2007;21(5):602-5.

8. Evans DM, Kirk KM, Nyholt DR, Novac C, Martin NG. Teenage acne is influenced by genetic factors. Br J Dermatol. 2005;152(3):579-81.

9. He L, Wu W-J, Yang J-K, Cheng H, Zuo X-B, Lai W, et al. Two new susceptibility loci $1 \mathrm{q} 24.2$ and 11 p11.2 confer risk to severe acne. Nat Commun. 2014;5:2870.

10. Navarini AA, Simpson MA, Weale M, Knight J, Carlavan I, Reiniche P, et al. Genome-wide association study identifies three novel susceptibility loci for severe Acne vulgaris. Nat Commun. 2014;5(1):4020.

11. Petridis C, Navarini AA, Dand N, Saklatvala J, Baudry D, Duckworth $M$, et al. Genome-wide meta-analysis implicates mediators of hair follicle development and morphogenesis in risk for severe acne. Nat Commun. 2018;9(1):5075.

12. Zhang M, Qureshi AA, Hunter DJ, Han J. A genome-wide association study of severe teenage acne in European Americans. Hum Genet. 2014;133(3):259-64.

13. Szabó K, Kemény L. Studying the genetic predisposing factors in the pathogenesis of acne vulgaris. Hum Immunol. 2011;72(9):766-73.

14. Lichtenberger R, Simpson MA, Smith C, Barker J, Navarini AA. Genetic architecture of acne vulgaris. J Eur Acad Dermatol Venereol. 2017;31(12):1978-90.

15. Common JEA, Barker JN, Steensel MAM. What does acne genetics teach us about disease pathogenesis? Br J Dermatol. 2019;181(4):665-76.

16. Moola S, Munn Z, Tufanaru C, Aromataris E, Sears K, Sfetcu R, Currie M, Qureshi R, Mattis P, Lisy K, Mu P-F. Chapter 7: Systematic reviews of etiology and risk. In: Aromataris E, Munn Z (Eds). JBI Manual for Evidence Synthesis. JBI, 2020. Available from https://synthesismanual.jbi.global.
17. Sorour NE, Mustafa Al, Alhusseni NF, Fawzy E, Amer AG. Angiotensin-converting enzyme gene insertion/deletion polymorphism and family history in severe acne vulgaris. J Cosmet Dermatol. 2019;18(6):1992-7.

18. Sobjanek M, Zablotna M, Glen J, Michajlowski I, Nedoszytko B, Rosz kiewicz J. Polymorphism in interleukin $1 \mathrm{~A}$ but not in interleukin 8 gene predisposes to acne vulgaris in Polish population: Letter to the Editor. J Eur Acad Dermatol Venereol. 2013;27(2):259-60.

19. Younis S, Javed Q. The interleukin-6 and interleukin-1A gene promoter polymorphism is associated with the pathogenesis of acne vulgaris. Arch Dermatol Res. 2015;307(4):365-70.

20. Ibrahim AA, Salem RM, El-Shimi OS, Baghdady SMA, Hussein S. IL IA (-889) gene polymorphism is associated with the effect of diet as a risk factor in Acne Vulgaris. J Cosmet Dermatol. 2019;18(1):333-6.

21. Szabó K, Tax G, Kis K, Szegedi K, Teodorescu-Brinzeu DG, Diószegi C, et al. Interleukin-1A + 4845(G> T) polymorphism is a factor predisposing to acne vulgaris. Tissue Antigens. 2010;76(5):411-5.

22. Akoglu G, Tan C, Ayvaz DC, Tezcan I. Tumor necrosis factor a-308 G/A and interleukin 1 B-511 C/T gene polymorphisms in patients with scarring acne. J Cosmet Dermatol. 2019:18(1):395-400.

23. Al Robaee AA, AlZolibani A, Al Shobaili H, Settin A. Association of interleukin 4 (-590 T/C) and interleukin 4 receptor (Q551R $\mathrm{A} / \mathrm{G})$ gene polymorphisms with acne vulgaris. Ann Saudi Med. 2012;32(4):349-54.

24. Al-Shobaili HA, Salem TA, Alzolibani AA, Robaee AA, Settin AA Tumor necrosis factor- $a-308 \mathrm{G} / \mathrm{A}$ and interleukin 10-1082 A/G gene polymorphisms in patients with acne vulgaris. J Dermatol Sci. 2012;68(1):52-5.

25. Soguktas H, Yaykasli KO, Turan H, Kaya E, Yaykasli E. Omentin Val/Val genotype increases predisposition to acne vulgaris without changing omentin serum level. Cell Mol Biol. 2018;64(12):81.

26. Ehm MG, Aponte $J$, Chiano MN, Yerges-Armstrong LM, Johnson T, Barker JN, et al. Phenome-wide association study using research participants' self-reported data provides insight into the Th17 and IL-17 pathway. PLoS ONE. 2017;12(11):e0186405.

27. Yaykasli KO, Turan H, Kaya E, Hatipoglu OF. Polymorphisms in the promoters of MMP-2 and TIMP-2 genes in patients with acne vulgaris. Int J Clin Exp Med. 2013;6(10):967-72.

28. Gao R, Yu H, Zhao Q, Wang S, Bai B. Role of MMP-2(-1306 C/T) and TIMP2(-418G/C) polymorphism in Chinese Han patients with Acne Vulgaris. BioMed Res Int. 2019;2019:1-7.

29. Hussain S, Faraz A, lqbal T. The RETN gene rs 1862513 polymorphism as a novel predisposing marker for familial Acne vulgaris in a Pakistani population. Iran J Basic Med Sci. 2015;18(5):526-8.

30. Younis $S$, Blumenberg M, Javed $Q$. Resistin gene polymorphisms are associated with acne and serum lipid levels, providing a potential nexus between lipid metabolism and inflammation. Arch Dermatol Res. 2016;308(4):229-37.

31. Koreck A, Kis K, Szegedi K, Paunescu V, Cioaca R, Olariu R, et al. TLR2 and TLR4 polymorphisms are not associated with Acne Vulgaris. Dermatology. 2006;213(3):267-9.

32. Tian L-M, Xie H-F, Yang T, Hu Y-H, Li J, Wang W-Z. Association study of tumor necrosis factor receptor type 2 M196R and toll-like receptor 2 Arg753GIn polymorphisms with Acne Vulgaris in a Chinese Han Ethnic Group. Dermatology. 2010;221(3):276-84.

33. Aisha NM, Haroon J, Hussain S, Tahir CM, Ikramullah M, Rahim H, et al. Association between tumour necrosis-a gene polymorphisms and acne vulgaris in a Pakistani population. Clin Exp Dermatol. 2016:41(3):297-301.

34. Sobjanek M, Zabłotna M, Nedoszytko B, Sokołowska-Wojdyło M, Włodarkiewicz A. Lack of association between the promoter polymorphisms at positions -238 and -308 of the tumour necrosis factor alpha gene and acne vulgaris in Polish patients. J Eur Acad Dermatol Venereol. 2009;23(3):331-2.

35. Szabó K, Tax G, Teodorescu-Brinzeu D, Koreck A, Kemény L. TNFa gene polymorphisms in the pathogenesis of acne vulgaris. Arch Dermatol Res. 2011;303(1):19-27.

36. Baz K, Emin Erdal M, Yazıcı AC, Söylemez F, Güvenç U, Taşdelen B, et al. Association between tumor necrosis factor-alpha gene promoter polymorphism at position -308 and acne in Turkish patients. Arch Dermatol Res. 2008;300(7):371-6. 
37. Grech I, Giatrakos S, Damoraki G, Kaldrimidis P, Rigopoulos D, Giamarellos-Bourboulis EJ. Impact of TNF haplotypes in the physical course of Acne Vulgaris. Dermatology. 2014;228(2):152-7.

38. Yang X, Wu W, Peng M, Shen Q, Feng J, Lai W, et al. Identity-by-descent analysis reveals susceptibility loci for severe Acne in Chinese Han Cohort. J Invest Dermatol. 2019;139(9):2049-2051.e20.

39. Pang Y, He C, Liu Y, Wang K, Xiao T, Wang Y, et al. Combination of short CAG and GGN repeats in the androgen receptor gene is associated with acne risk in North East China. J Eur Acad Dermatol Venereol. 2008;22(12):1445-51.

40. Yang Z, Yu H, Cheng B, Tang W, Dong Y, Xiao C, et al. Relationship between the CAG repeat polymorphism in the androgen receptor gene and acne in the Han Ethnic Group. Dermatology. 2009;218(4):302-6.

41. Demirkan S, Sayın DB, Gündüz Ö. CAG polymorphism in the androgen receptor genein women may be associated with nodulocystic acne. Adv Dermatol Allergol. 2019;36(2):173-6.

42. Sawaya ME, Shalita AR. Androgen receptor polymorphisms (CAG repeat lengths) in Androgenetic Alopecia, Hirsutism, and Acne. J Cutan Med Surg. 1998;3(1):9-15.

43. Chamaie-Nejad F, Saeidi S, Najafi F, Ebrahimi A, Rahimi Z, Shakiba E, et al. Association of the CYP17 MSP Al (T-34C) and CYP19 codon 39 (Trp/Arg) polymorphisms with susceptibility to acne vulgaris. Clin Exp Dermatol. 2018:43(2):183-6.

44. Malikova N, Karimov K, Boboev K, Arifov S. The CYP17A1 rs743572 gene polymorphism and risk of development and clinical features of Acne Vulgaris in the Uzbek population. Int J Biomed. 2019;9(2):125-7.

45. He L, Yang Z, Yu H, Cheng B, Tang W, Dong Y, et al. The Relationship between CYP17-34T/C polymorphism and acne in Chinese subjects revealed by sequencing. Dermatology. 2006;212(4):338-42.

46. Ebrahimi A, Rahimi Z, Ghadami Z, Shakiba E, Rahimi Z, Akbari M, et al. Association between CYP19A<G rs700518 Polymorphism with Acne Vulgaris and its severity: influence on sex hormones level. Int J Mol Cell Med. 2019;8(2):162-8.

47. Darmani E, Darwin E, Damayanti I, Nurdin AE. Genetic polymorphism in CYP1A1 affected susceptibility to acne vulgaris in Pekanbaru Indonesian Population, Desember 2013-Maret 2014. Bali Med J. 2019;8(1):169.

48. Paraskevaidis A, Drakoulis N, Roots I, Orfanos CE, Zouboulis ChC. Polymorphisms in the human cytochrome P-450 1A1 gene (CYP1A1) as a factor for developing acne. Dermatology. 1998;196(1):171-5.

49. El-Tahlawi SMR, Abdel-Halim MRE, Abdel Hamid MF, Mohammad KS, Wafai H, El-Sayed AHMS. Gene polymorphism and serum levels of insulin-like growth factor-l in Egyptian acne patients. J Egypt Women's Dermatol Soc. 2014;11(1):45-9.

50. Rahaman SMA, De D, Handa S, Pal A, Sachdeva N, Ghosh T, et al. Association of insulin-like growth factor (IGF)-1 gene polymorphisms with plasma levels of IGF-1 and acne severity. J Am Acad Dermatol. 2016;75(4):768-73.

51. Tasli L, Turgut S, Kacar N, Ayada C, Coban M, Akcilar R, et al. Insulinlike growth factor-I gene polymorphism in acne vulgaris: IGF-1 gene polymorphism in acne vulgaris. J Eur Acad Dermatol Venereol. 2013;27(2):254-7.

52. Farag AGA, Badr EA, Eltorgoman AMA, Assar MF, Elshafey EN, Tayel NR, et al. Role of 11\&beta; HSD 1, rs12086634, and rs846910 singlenucleotide polymorphisms in metabolic-related skin diseases: a clinical, biochemical, and genetic study. Clin Cosmet Investig Dermatol. 2019;12:91-102

53. Yang $X-Y$, Wu W-J, Yang C, Yang T, He J-D, Yang Z, et al. Association of HSD17B3 and HSD3B1 polymorphisms with acne vulgaris in Southwestern Han Chinese. Dermatol Basel Switz. 2013;227(3):202-8.

54. Ando I, Kukita A, Soma G, Hino H. A large number of tandem repeats in the polymorphic epithelial mucin gene is associated with severe acne. $J$ Dermatol. 1998;25(3):150-2.

55. Amr K, Abdel-Hameed M, Sayed K, Nour-Edin F, Abdel HR. The Pro12Ala polymorphism of the gene for peroxisome proliferator activated receptor-gamma is associated with a lower Global Acne Grading System score in patients with acne vulgaris. Clin Exp Dermatol. 2014;39(6):741-5

56. Saeidi S, Chamaie-Nejad F, Ebrahimi A, Najafi F, Rahimi Z, VaisiRaygani A, et al. PPARy Pro12Ala and C161T polymorphisms in patients with acne vulgaris: contribution to lipid and lipoprotein profile. Adv Med Sci. 2018;63(1):147-51.

57. Hu X, Ding W, Jin X, Wang J, Zou D, Chen Y. Longer TA repeat but not V89L polymorphisms in the SRD5A2 gene may confer acne risk in the Chinese population. Adv Dermatol Allergol. 2018;35(1):33-8.

58. Swelam MM, El-Barbary RAH, Saudi WM, Fathi MS, Soliman DA, Abd Elrehem $\mathrm{HH}$. Associations among two vitamin D receptor (VDR) gene polymorphisms (Apal and Taql) in acne vulgaris: a pilot susceptibility study. J Cosmet Dermatol. 2019;18(4):1113-20.

59. Aydingoz IE, Demirci GT, Agirbasli D, Oz-Arslan D, Yenmis G. The investigation of the amounts and expressions of epidermal growth factor, epidermal growth factor receptor, and epidermal growth factor receptor gene polymorphisms in acne vulgaris. J Cosmet Dermatol [Internet]. [cited 2020 Oct 29]; Available from: https://doi. org/10.1111/jocd.13498

60. Ragab M, Hassan EM, Elneily D, Fathallah N. Association of interleukin-6 gene promoter polymorphism with acne vulgaris and its severity. Clin Exp Dermatol. 2019;44(6):637-42.

61. Hussain S, Iqbal T, Sadiq I, Feroz S, Shafique SH. Polymorphism in the IL-8 gene promoter and the risk of Acne Vulgaris in a Pakistani population. Iran J Allergy Asthma Immunol. 2015;14(4):443-9.

62. Yang J-K, Wu W-J, Qi J, He L, Zhang Y-P. TNF -308 G/A polymorphism and risk of Acne Vulgaris: a meta-analysis. PLOS ONE. 2014:9(2):e87806.

63. Ferguson LR, Huebner C, Petermann I, Gearry RB, Barclay ML, Demmers $P$, et al. Single nucleotide polymorphism in the tumor necrosis factor-alpha gene affects inflammatory bowel diseases risk. World J Gastroenterol. 2008;14(29):4652-61.

64. van Heel DA, Udalova IA, De Silva AP, McGovern DP, Kinouchi Y, Hull J, et al. Inflammatory bowel disease is associated with a TNF polymorphism that affects an interaction between the OCT1 and NF(-kappa)B transcription factors. Hum Mol Genet. 2002;11(11):1281-9.

65. Kawaguchi Y, Tochimoto A, Hara M, Kawamoto M, Sugiura T, Saito S, et al. Contribution of single nucleotide polymorphisms of the IL1A gene to the cleavage of precursor IL-1alpha and its transcription activity. Immunogenetics. 2007;59(6):441-8.

66. Lee S, Temple S, Roberts S, Price P. Complex effects of IL1A polymorphism and calpain inhibitors on interleukin 1 alpha (IL-1 alpha) mRNA levels and secretion of IL-1 alpha protein. Tissue Antigens. 2008;72(1):67-71

67. Kobayashi Y, Yamamoto K, Saido T, Kawasaki H, Oppenheim JJ, Matsushima K. Identification of calcium-activated neutral protease as a processing enzyme of human interleukin 1 alpha. Proc Natl Acad Sci USA. 1990;87(14):5548-52.

68. Ferwerda B, McCall MBB, Alonso S, Giamarellos-Bourboulis EJ, Mouktaroudi M, Izagirre N, et al. TLR4 polymorphisms, infectious diseases, and evolutionary pressure during migration of modern humans. Proc Natl Acad Sci USA. 2007;104(42):16645-50.

69. Ferwerda B, McCall MB, Verheijen K, Kullberg B-J, van der Ven AJ, Van der Meer JW, et al. Functional consequences of toll-like receptor 4 polymorphisms. Mol Med. 2008;14(5-6):346-52.

70. Malhotra D, Relhan V, Reddy BSN, Bamezai R. TLR2 Arg677Trp polymorphism in leprosy: revisited. Hum Genet. 2005;116(5):413-5.

71. Brown RA, Gralewski JH, Eid AJ, Knoll BM, Finberg RW, Razonable RR. R753Q single nucleotide polymorphism impairs toll-like receptor 2 recognition of hepatitis $\mathrm{C}$ virus core and nonstructural 3 proteins. Transplantation. 2010;89(7):811-5.

72. Brown RA, Gralewski JH, Razonable RR. The R753Q polymorphism abrogates toll-like receptor 2 signaling in response to human cytomegalovirus. Clin Infect Dis Off Publ Infect Dis Soc Am. 2009:49(9):e96-9.

73. Shen C, Wang QZ, Shen ZY, Yuan HY, Yu WJ, Chen XD, et al. Genetic association between the NLRP3 gene and acne vulgaris in a Chinese population. Clin Exp Dermatol. 2019;44(2):184-9.

74. Carey AH, Waterworth D, Patel K, White D, Little J, Novelli P, et al. Polycystic ovaries and premature male pattern baldness are associated with one allele of the steroid metabolism gene CYP17. Hum Mol Genet. 1994;3(10):1873-6.

75. Nedelcheva Kristensen V, Haraldsen EK, Anderson KB, Lønning PE, Erikstein B, Kåresen R, et al. CYP17 and breast cancer risk: the polymorphism in the $5^{\prime}$ flanking area of the gene does not influence binding to Sp-1. Cancer Res. 1999;59(12):2825-8. 
76. Chamberlain NL, Driver ED, Miesfeld RL. The length and location of CAG trinucleotide repeats in the androgen receptor $\mathrm{N}$-terminal domain affect transactivation function. Nucleic Acids Res. 1994;22(15):3181-6.

77. Kazemi-Esfarjani P, Trifiro MA, Pinsky L. Evidence for a repressive function of the long polyglutamine tract in the human androgen receptor: possible pathogenetic relevance for the (CAG)n-expanded neuronopathies. Hum Mol Genet. 1995;4(4):523-7.

78. Choong CS, Kemppainen JA, Zhou ZX, Wilson EM. Reduced androgen receptor gene expression with first exon CAG repeat expansion. Mol Endocrinol Baltim Md. 1996;10(12):1527-35.

79. Choong CS, Wilson EM. Trinucleotide repeats in the human androgen receptor: a molecular basis for disease. J Mol Endocrinol. 1998;21(3):235-57.

80. Kim J. Review of the innate immune response in acne vulgaris: activation of toll-like receptor 2 in acne triggers inflammatory cytokine responses. Dermatology. 2005;211(3):193-8.

81. Dreno B, Gollnick HPM, Kang S, Thiboutot D, Bettoli V, Torres V, et al. Understanding innate immunity and inflammation in acne: implications for management. J Eur Acad Dermatol Venereol. 2015;29:3-11.

82. Zelová H, Hošek J. TNF-a signalling and inflammation: interactions between old acquaintances. Inflamm Res. 2013;62(7):641-51.

83. Pang SS, Le YY. Role of resistin in inflammation and inflammationrelated diseases. Cell Mol Immunol. 2006;3(1):29-34.

84. Kim JM, Choo JE, Lee HJ, Kim KN, Chang SE. Epidermal growth factor attenuated the expression of inflammatory cytokines in human epidermal keratinocyte exposed to Propionibacterium acnes. Ann Dermatol. 2018;30(1):54

85. Nakagawa Y, Takamatsu H, Okuno T, Kang S, Nojima S, Kimura T, et al. Identification of semaphorin $4 \mathrm{~B}$ as a negative regulator of basophilmediated immune responses. J Immunol. 2011;186(5):2881-8.

86. Li X, Jia Y, Wang S, Meng T, Zhu M. Identification of genes and pathways associated with acne using integrated bioinformatics methods. Dermatology. 2019;235(6):445-55.

87. Chen B, Zheng Y, Liang Y. Analysis of potential genes and pathways involved in the pathogenesis of acne by bioinformatics. BioMed Res Int 2019;2019:1-8.

88. Makrantonaki E, Ganceviciene R, Zouboulis CC. An update on the role of the sebaceous gland in the pathogenesis of acne. Dermatoendocrinol. 2011;3(1):41-9.
89. Krämer C, Seltmann H, Seifert M, Tilgen W, Zouboulis CC, Reichrath J. Characterization of the vitamin $D$ endocrine system in human sebocytes in vitro. J Steroid Biochem Mol Biol. 2009;113(1-2):9-16.

90. Spencer EH, Ferdowsian HR, Barnard ND. Diet and acne: a review of the evidence. Int J Dermatol. 2009;48(4):339-47.

91. Steensel MAM. From genome-wide association to biological explanation. Br J Dermatol. 2019;181(6):1113-4.

92. Saadi I, Alkuraya FS, Gisselbrecht SS, Goessling W, Cavallesco R, TurbeDoan A, et al. Deficiency of the cytoskeletal protein SPECC1L leads to oblique facial clefting. Am J Hum Genet. 2011;89(1):44-55.

93. Leyden J, Stein-Gold L, Weiss J. Why topical retinoids are mainstay of therapy for acne. Dermatol Ther. 2017;7(3):293-304.

94. Bagatin E, Timpano DL, dos Guadanhim LRS, Nogueira VMA, Terzian LR, Steiner D, et al. Acne vulgaris: prevalence and clinical forms in adolescents from São Paulo. Brazil An Bras Dermatol. 2014;89(3):428-35.

95. Li H-L, Song J, Yong H-M, Hou P-F, Chen Y-S, Song W-B, et al. PinX1: structure, regulation and its functions in cancer. Oncotarget. 2016;7(40):66267-75.

96. Muszbek L, Bereczky Z, Bagoly Z, Komáromi I, Katona É. Factor XIII: a coagulation factor with multiple plasmatic and cellular functions. Physiol Rev. 2011;91(3):931-72.

97. Liu H, Ippolito GC, Wall JK, Niu T, Probst L, Lee B-S, et al. Functional studies of BCL11A: characterization of the conserved BCL11A-XL splice variant and its interaction with BCL6 in nuclear paraspeckles of germinal center B cells. Mol Cancer. 2006;5(1):18.

98. Marlaire S, Van Schaftingen E, Veiga-da-Cunha M. C7orf10 encodes succinate-hydroxymethylglutarate CoA-transferase, the enzyme that converts glutarate to glutaryl-CoA. J Inherit Metab Dis. 2014;37(1):13-9.

99. Mill P. Sonic hedgehog-dependent activation of $\mathrm{Gli} 2$ is essential for embryonic hair follicle development. Genes Dev. 2003;17(2):282-94.

100. Hirschhorn JN, Lohmueller K, Byrne E, Hirschhorn K. A comprehensive review of genetic association studies. Genet Med Off J Am Coll Med Genet. 2002;4(2):45-61.

\section{Publisher's Note}

Springer Nature remains neutral with regard to jurisdictional claims in published maps and institutional affiliations.
Ready to submit your research? Choose BMC and benefit from:

- fast, convenient online submission

- thorough peer review by experienced researchers in your field

- rapid publication on acceptance

- support for research data, including large and complex data types

- gold Open Access which fosters wider collaboration and increased citations

- maximum visibility for your research: over $100 \mathrm{M}$ website views per year

At BMC, research is always in progress.

Learn more biomedcentral.com/submissions 